\title{
Expert Elicitation to Estimate the Relative Risk of Food Safety Criteria Included in the Establishment-Based Risk Assessment Model for Canadian Hatcheries
}

\author{
Manon Racicot, ${ }^{1}$ Geneviève Comeau, ${ }^{1}$ Alexandre Leroux, ${ }^{2}$ Sylvain Quessy, ${ }^{3}$ Sunny $\mathrm{Ng}^{2}$ \\ Teresa Cereno, ${ }^{2}$ Daniel Venne, ${ }^{4}$ Ghislain Hébert, ${ }^{5}$ Jean-Pierre Vaillancourt, ${ }^{3}$ Philippe Fravalo, ${ }^{3}$ \\ Rachel Ouckama, ${ }^{6}$ Darko Mitevski, ${ }^{7}$ Michele T. Guerin, ${ }^{8}$ Agnes Agunos, ${ }^{9}$ Leanne DeWinter, ${ }^{10}$ \\ Angela Catford, ${ }^{10}$ and Marie-Lou Gaucher ${ }^{3}$
}

\begin{abstract}
The Canadian Food Inspection Agency is developing an Establishment-based Risk Assessment model for Hatcheries to allocate inspection resources according to the food safety risk associated with each hatchery falling under its jurisdiction. In a previous study, 29 factors contributing to the food safety risk of hatcheries were identified and grouped into three clusters (inherent risk, risk mitigation, and compliance) and assessment criteria were defined. The objective of the current study was to estimate the relative risk (RR) of these criteria. Two rounds of expert elicitations were conducted to allow 13 Canadian experts to estimate the RR of each criterion $(n=96)$ based on its potential impact on human health, with a specific focus on Salmonella spp. This process also aimed to estimate the maximum increase or decrease in the overall food safety risk of a hatchery when considering multiple criteria belonging to a specific cluster and to assess the risk attribution of Salmonella spp. at the hatchery and bird-type levels. Results showed that the respondent profile had no influence on the importance given to a majority of criteria. Uniformity of answers among experts improved from the first to the second round. Overall, $62.5 \%, 32.3 \%$, and $5.2 \%$ of the criteria were attributed to an RR that was less than 2, between 2 and 3, and greater than 3, respectively. Mixing eggs from different supply flocks when placed into the same hatching unit, hatching multiple species, and importing eggs with unknown quality status were identified as having the highest contribution to a hatchery's inherent risk. Requiring information on the foodborne pathogen status of supplying flocks and the occurrence of regulatory enforcement actions were the most impactful risk mitigation and compliance factors, respectively. The median RR value assigned to each criterion and cluster will be used to build this new model.
\end{abstract}

Keywords: poultry, public health, food safety, Salmonella, hatchery, quantitative risk assessment, risk-based inspection, expert elicitation

\section{Introduction}

$\mathbf{N}$ ONTYPHOIDAL SALMONELLAE ARE the second-most burdensome, domestically acquired foodborne pathogens in Canada, after Campylobacter (Havelaar et al., 2012; Tho- mas et al., 2013; Butler et al., 2015). According to Canadian experts, $\sim 24 \%$ and $11 \%$ of foodborne illnesses in humans associated with Salmonella spp. are attributed to the consumption of contaminated poultry meat and eggs, respectively (Butler et al., 2016). In Canada, efforts are implemented at all

${ }^{1}$ Canadian Food Inspection Agency, St-Hyacinthe, Canada.

${ }^{2}$ Canadian Food Inspection Agency, Ottawa, Canada.

${ }^{3}$ Faculté de médecine vétérinaire, Université de Montréal, St-Hyacinthe, Canada.

${ }^{4}$ Couvoir Scott ltée, Scott, Canada.

${ }^{5}$ Les Couvoiriers du Québec, St-Hyacinthe, Canada.

${ }^{6}$ Maple Lodge Hatcheries Ltd., Port Hope, Canada.

${ }^{7}$ Poultry Health Services, Airdrie, Canada.

${ }^{8}$ Department of Population Medicine, Ontario Veterinary College, University of Guelph, Guelph, Canada.

${ }^{9}$ Public Health Agency of Canada, Guelph, Canada.

${ }^{10}$ Health Canada, Ottawa, Canada. 
levels of the poultry meat and egg production chains to reduce the public health impact of this zoonotic pathogen. From a regulatory perspective, risk-based oversight is also needed to optimize the allocation of inspection resources.

Within this context, the Canadian Food Inspection Agency (CFIA) developed quantitative risk assessment models aimed at prioritizing oversight based on the food safety risk associated with their regulated parties (CFIA, 2019a). One of these models - the Establishment-based Risk Assessment model for Hatcheries (ERA-H) - aims to quantify the food safety risk associated with the products derived from Canadian hatcheries based on the impact of Salmonella spp. on public health, these foods including poultry meat, eggs, and fertilized eggs (balut). In Canada, hatcheries with an incubation capacity of 1000 eggs or more fall under CFIA's jurisdiction. Our group previously selected 29 food safetyrelated risk factors and 96 assessment criteria that should be included in this model (Racicot et al., 2019).

The objective of the current study was to estimate the relative risk (RR) of each criterion using an expert elicitation and to assess the maximum increase or decrease in the level of risk obtained when multiple criteria belonging to the same cluster were identified in a specific hatchery. This process also aimed to assess the risk attribution of Salmonella spp. at the hatchery and bird-type levels.

\section{Materials and Methods}

A web-based questionnaire was developed using SimpleSurvey (OutSide Soft Solutions, inc., Québec, Canada). The questionnaire was pretested, in English and French, by three experts from the CFIA and the Universite de Montréal. The questionnaire was administered to members of the Scientific Advisory Committee (SAC) on March 22, 2017. The SAC consisted of 15 hatchery and/or food safety experts from across Canada. Participants were gathered in one room, yet completed the questionnaire individually over a $2-\mathrm{h}$ period (first round). Guidelines for completing the questionnaire and a glossary of terms were made available.

The first section of the questionnaire pertained to the expert's profile, including questions on the number of years of professional experience, the current employment sector, the highest degree held, and the field of expertise. The second section required the expert to estimate the relative contribution of each stage along the poultry meat and egg production chains and each type of bird hatched in Canadian hatcheries to the Salmonella spp. burden in poultry meat and egg products. The third section required the expert to estimate the $\mathrm{RR}$ associated with each criterion and to assess the maximum increase or decrease in the level of risk when multiple criteria belonging to a same cluster (inherent risk, risk mitigation, or compliance) were identified in a hatchery. To ensure all participants would provide estimates on a comparable scale, the concept of RR was explained: "If a hatchery is responsible for 100 human illnesses, a criterion with a RR of 2 would increase the contribution of this hatchery to the Salmonella burden by a factor of 2 , which would translate into 200 human illnesses."

Data from the first round were compiled using Microsoft Office Excel 2013 (Microsoft Corporation, Redmond, WA). Summarized results were shared with the participants in a printed report during the afternoon session. For each criterion and cluster, the report presented the following: (1) the number of respondents; (2) the minimum and maximum RR values; and (3) the first quartile (Q1), the median (Q2), and the third quartile (Q3) values. Using this information, participants were asked to compare their responses with those provided by the other experts. During the second round, participants raised technical questions, which were then discussed by the group to share points of view on the weighting assigned to each criterion. Participants were then invited to reconnect to their own web-based questionnaire and to modify their RR as they thought necessary. Data derived from the second round were compiled in the same manner as the first. At the end of the meeting, participants were given the opportunity to suggest, within 2 weeks, other assessment criteria that were not included in the questionnaire.

Due to the proposal of some additional criteria, a second expert elicitation was organized. A similar approach was adopted, although conducted electronically. Previous participants received an e-mail on August 28, 2017, that included a personalized link to a web-based questionnaire (SimpleSurvey), a copy of the guidelines provided in March 2017, a glossary, and the results of the first elicitation to ensure a consistent approach between the two elicitation processes. Participants were given 2 weeks to complete the questionnaire (first round). The second round took place on September 26, 2017, via WebEx (Cisco Systems, Inc., San Jose, CA).

Statistical analyses were performed using R Programming environment (3.2.2, 2015-08-14; R Foundation for Statistical Computing, Vienna, Austria) to evaluate whether there were significant differences among experts' final responses depending on their employment sector (industry vs. government vs. academia) and number of years of professional experience ( $\leq 15$ vs. $>15$ years). To compare median values obtained from the second round of both expert elicitations, the nonparametric Kruskal-Wallis test for non-normally distributed data was used (Hollander and Wolfe, 1973). The method described by Benjamini and Hochberg (1995) was applied to control for the false discovery rate. To quantify the degree of uncertainty around each median, a distribution-free 95\% confidence interval for percentiles was calculated (Hogg and Tanis, 2010). In addition, coefficients of quartile variation were investigated to evaluate experts' agreement from the first to the second round (Bonett, 2006).

\section{Results}

Thirteen members of the SAC voluntarily participated in the first expert elicitation conducted in March 2017 (one expert from Alberta, six from Ontario, and six from Québec). Of those, 12 participated in the second elicitation. The number of years of professional experience in the areas of hatcheries and/or food safety for all participating experts ranged from 7 to 33 (mean $\pm S D=18 \pm 8.2$ ). At the time the elicitation was conducted, five participants (38.5\%) were working for regulatory institutions and/or government, five $(38.5 \%)$ for universities, colleges, and/or research institutions, and three $(23 \%)$ were involved in the poultry industry. Past experience in the poultry industry was reported by three experts from government and academia. Experts were asked to provide information on their highest degree obtained: five 
Table 1. Number of Respondents $(N)$, Median VALUe (Q2), AND 95\% CONFIDENCE INTERVAL FOR THE MEDIAN Estimated by EXPERTS For the Contribution (\%) of Each Poultry Production Stage to the Salmonella SPP. Burden in Poultry Meat Products

\begin{tabular}{|c|c|c|c|c|c|c|}
\hline \multirow{2}{*}{$\begin{array}{l}\text { Poultry meat } \\
\text { production chain }\end{array}$} & \multicolumn{3}{|c|}{ First round } & \multicolumn{3}{|c|}{ Second round } \\
\hline & $\mathrm{n}$ & $Q 2$ & $95 \% C I$ & $\mathrm{n}$ & $Q 2$ & $95 \% C I$ \\
\hline Breeder farms & 13 & 20 & $10-45$ & 13 & 20 & $20-30$ \\
\hline $\begin{array}{l}\text { Hatcheries (including } \\
\text { transportation to } \\
\text { the rearing facility) }\end{array}$ & 13 & 10 & $5-30$ & 13 & 10 & $10-20$ \\
\hline Rearing facilities & 13 & 25 & $20-30$ & 13 & 30 & $25-35$ \\
\hline Transport & 13 & 6 & $5-10$ & 13 & 5 & $5-10$ \\
\hline $\begin{array}{l}\text { Slaughterhouse/ } \\
\text { processing/storage/ } \\
\text { transportation }\end{array}$ & 13 & 30 & $15-40$ & 13 & 30 & $20-35$ \\
\hline
\end{tabular}

CI, confidence interval.

experts (38\%) reported holding a $\mathrm{PhD}$ degree, three $(23 \%)$ held a Master's degree, and five $(38 \%)$ held a Doctor of Veterinary Medicine (DVM) degree. Experts' fields of competence included veterinary medicine $(46 \%)$, microbiology (23\%), epidemiology (15\%), biology (8\%), and engineering $(8 \%)$.

Tables 1 to 4 present the attribution of risk along the poultry meat and egg production chains, and across the different types of birds hatched in Canadian hatcheries, to the Salmonella spp. burden in poultry meat and egg products. Tables 5 to 8 present the number of respondents, median RR value (Q2), and 95\% confidence interval of the median for each assessment criterion and cluster for the first and second rounds of the elicitation. Based on the values obtained from the second round, $63 \%, 32 \%$, and $5 \%$ of the assessment criteria were given a RR of $<2$, between 2 and 3, and $>3$, respectively (Table 9). Criteria related to regulatory enforcement actions were attributed the highest RR by the experts. The median maximum increase or decrease in the RR for each cluster (with 95\% confidence interval) was as fol-

Table 2. Number of Respondents ( $N$ ), Median VALUe (Q2), AND 95\% CONFIDENCE INTERVAL FOR THE MEDIAN Estimated by EXPERTS for the Contribution (\%) OF EACH EgG Production Stage to THE $S_{A L M O N E L L A}$ SPP. BuRdeN IN EgG Products

\begin{tabular}{llllllll}
\hline & \multicolumn{3}{c}{ First round } & & \multicolumn{3}{c}{ Second round } \\
\cline { 2 - 3 } \cline { 6 - 7 } Egg production chain & $\mathrm{n}$ & $Q 2$ & $95 \%$ CI & & $\mathrm{n}$ & $Q 2$ & $95 \%$ CI \\
\hline $\begin{array}{l}\text { Breeder farms } \\
\text { Hatcheries (including }\end{array}$ & 13 & 30 & $20-45$ & & 12 & 30 & $25-40$ \\
$\begin{array}{c}\text { transportation to } \\
\text { the rearing facility) }\end{array}$ & 15 & $10-20$ & & 12 & 17.5 & $10-20$ \\
$\begin{array}{c}\text { Rearing/production } \\
\text { facilities }\end{array}$ & 13 & 40 & $25-40$ & 12 & 40 & $25-40$ \\
$\begin{array}{c}\text { Processing/storage/ } \\
\text { transportation }\end{array}$ & 13 & 10 & $5-25$ & 12 & 10 & $5-20$ \\
\hline
\end{tabular}

CI, confidence interval.
Table 3. Number of Respondents ( $N$ ), Median

VAlue (Q2), and 95\% CONFIDENCE INTERVAL FOR THE MEDIAN EsTIMATED BY EXPERTS

For the Attribution (\%) to the Different Types of Birds Derived From Hatcheries in the Poultry

Meat Production Chain of the SaLMonella SPP. Burden in Poultry Meat Products

\begin{tabular}{|c|c|c|c|c|c|c|}
\hline \multirow[b]{2}{*}{ Type of birds } & \multicolumn{3}{|c|}{ First round } & \multicolumn{3}{|c|}{ Second round } \\
\hline & $\mathrm{n}$ & $Q^{2}$ & $95 \% C I$ & $\mathrm{n}$ & $Q^{2}$ & $95 \% C I$ \\
\hline Broilers & 13 & 50 & $30-70$ & 13 & 50 & $35-70$ \\
\hline Breeders & 13 & 10 & $5-20$ & 13 & 10 & $5-10$ \\
\hline $\begin{array}{l}\text { Layers (i.e., spent } \\
\text { hens, end-of-lay hens) }\end{array}$ & 13 & 10 & $5-10$ & 13 & 10 & $5-10$ \\
\hline Turkeys & 13 & 15 & $10-20$ & 13 & 15 & $10-20$ \\
\hline Waterfowl & 13 & 5 & $2.5-10$ & 13 & 8 & $3-10$ \\
\hline Game birds & 13 & 5 & $2-10$ & 13 & 5 & $2-10$ \\
\hline Others & 13 & 0 & $0-0$ & 13 & 0 & $0-0$ \\
\hline
\end{tabular}

CI, confidence interval.

lows: 5 (3-10), $6(5-10)$, and 10 (5-20) for the inherent risk, risk mitigation, and compliance cluster, respectively.

Histograms showing the RR estimated by the experts during the second round for each criterion and cluster are presented in Appendix Figure A1. The majority of the 100 histograms (96 criteria and 4 clusters; the compliance cluster was assessed both during the March and September elicitations) showed a skewed distribution. Indeed, $63 \%$ of the histograms were highly skewed to the right with a skewness $>1$ (Bulmer, 1979). Bar charts representing the median RR and $95 \%$ confidence interval for each criterion (second round), by cluster, are presented in Appendix Figure A2.

Overall, there was better agreement among the experts in their RR estimates in the second round. Compared with the first round, the coefficients of quartile variation during the second round were lower for $51 \%$ of the criteria and unchanged for $40 \%$ of the criteria. The median RR values did not significantly depend on the experts' employment sector nor on the number of years of professional experience after adjustment for multiple comparisons.

Table 4. Number of Respondents ( $N$ ), Median VAlue (Q2), AND 95\% CONFIDENCE INTERVAL FOR THE MEDIAN Estimated By EXPERTS For the AtTribution (\%) TO THE DiffERENT TyPes OF Birds Derived From Hatcheries IN THE EGG Production Chain of the SALMonella SPP. Burden IN Egg Products

\begin{tabular}{lrrrrrrrr}
\hline & \multicolumn{3}{c}{ First round } & & \multicolumn{3}{c}{ Second round } \\
\cline { 2 - 4 } \cline { 8 - 9 } Type of birds & $\mathrm{n}$ & $Q 2$ & $95 \%$ CI & & $\mathrm{n}$ & $Q 2$ & $95 \%$ \\
\hline Breeders & 13 & 10 & $5-30$ & & 12 & 22.5 & $10-30$ \\
Layers & 13 & 55 & $30-84$ & & 12 & 57.5 & $40-80$ \\
Waterfowl & 13 & 10 & $5-15$ & & 12 & 10 & $5-15$ \\
Game birds & 13 & 10 & $4-15$ & & 12 & 10 & $5-10$ \\
Others & 13 & 0 & $0-0$ & & 12 & 0 & \\
\hline
\end{tabular}

CI, confidence interval. 
Table 5. Number of Respondents ( $N$ ), Median Relative Risk Value (Q2), and 95\% Confidence Interval for the Median Estimated by EXPerts for Assessment Criteria Related TO The InHERent Risk Factor Cluster (March 2017)

\begin{tabular}{|c|c|c|c|c|c|c|}
\hline \multirow[b]{2}{*}{ Criteria } & \multicolumn{3}{|c|}{ First round } & \multicolumn{3}{|c|}{ Second round } \\
\hline & $\mathrm{n}$ & $Q 2$ & $95 \% C I$ & $\mathrm{n}$ & $Q 2$ & $95 \% C I$ \\
\hline $\begin{array}{l}\text { 1. What would be the increase in risk given to a hatchery that mixes eggs from } \\
\text { different supply flocks when placed into the hatchers compared with a hatchery } \\
\text { that does not mix eggs from different supply flocks? }\end{array}$ & 12 & 2 & $1.2-3$ & 13 & 2 & $1.5-2.5$ \\
\hline \multirow{3}{*}{$\begin{array}{l}\text { 2. Unexpected } \\
\text { surge demands What would be the increase in risk given to a hatchery that } \\
\text { goes frequently (e.g., more than } 10 \text { times in the past year) for } \\
\text { unexpected surge demands for imported eggs (spot market) } \\
\text { compared with a hatchery that does not? } \\
\text { (ii) What would be the increase in risk given to a hatchery that } \\
\text { goes occasionally (e.g., between } 3 \text { and } 10 \text { times in the past } \\
\text { year) for unexpected surge demands for imported eggs (spot } \\
\text { market) compared with a hatchery that does not? } \\
\text { (iii) What would be the increase in risk given to a hatchery that } \\
\text { goes rarely (e.g., less than three times in the past year) for } \\
\text { unexpected surge demands for imported eggs (spot market) }\end{array}$} & 13 & 2 & $1.5-5$ & 13 & 2 & $1.5-5$ \\
\hline & 13 & 1.5 & $1.3-3$ & 13 & 1.5 & $1.3-3$ \\
\hline & 13 & 1.2 & $1.1-1.5$ & 13 & 1.2 & $1.1-1.5$ \\
\hline $\begin{array}{l}\text { 3. What would be the increase in risk given to a hatchery for which incubator trolleys } \\
\text { are fixed rather than removable (to ease shell debris removal)? }\end{array}$ & 13 & 1.5 & $1.1-2$ & 13 & 1.5 & $1.1-2$ \\
\hline $\begin{array}{l}\text { 4. What would be the increase in risk given to a hatchery that uses an evaporative } \\
\text { cooling ventilation system compared with a hatchery where an air conditioning } \\
\text { system is used? }\end{array}$ & 12 & 1.2 & $1.1-1.5$ & 13 & 1.2 & $1.1-1.5$ \\
\hline $\begin{array}{l}\text { 5. What would be the increase in risk given to a hatchery that hatches multiples species } \\
\text { (e.g., chickens and turkeys, game birds and waterfowl) compared with a hatchery not } \\
\text { hatching multiple species? }\end{array}$ & 13 & 2 & $1.5-3$ & 13 & 2 & $1.5-3$ \\
\hline $\begin{array}{l}\text { 6. What would be the increase in risk given to a hatchery that hatches eggs for multiple } \\
\text { sectors (e.g., broiler chickens and broiler breeder chickens, broiler chickens and layer } \\
\text { chickens) compared with a hatchery that does not? }\end{array}$ & 12 & 1.5 & $1.2-2$ & 12 & 1.5 & $1.2-2$ \\
\hline $\begin{array}{l}\text { 7. What would be the maximum increase in risk given to a hatchery in which all the } \\
\text { abovementioned inherent risk factors are present? }\end{array}$ & 12 & 4 & $2-10$ & 11 & 5 & $3-10$ \\
\hline
\end{tabular}

CI, confidence interval.

\section{Discussion}

The current study estimated the RR of criteria for the new ERA-H model. A total of 13 Canadian hatchery and/or food safety experts, with significant experience (18 years on average) and knowledge, and who collectively represented all key employment sectors took part in an expert elicitation process. According to Delbecq et al. (1975, p. 174), 10 to 15 individuals are sufficient in a Delphi process when participants are homogeneous (e.g., specific expertise), which was the case for this study. Results showed that the range of RR values attributed by experts to the criteria narrowed between rounds 1 and 2, or remained unchanged; hence, having more than two rounds for the elicitation was deemed unnecessary.

Experts were initially asked to estimate the health burden of Salmonella spp. in humans that was attributed to each stage of the poultry meat and egg production chains, and to each poultry species. For poultry meat products, experts pointed out that the relative contribution of the rearing facilities and of the slaughter/processing plants were dominant. This result is in accordance with previous studies that identified rearing, transportation, and slaughtering stages as key influencers for the contamination of poultry meat products with Salmonella spp. (Heyndrickx et al., 2002; Namata et al., 2009; Bucher et al., 2012; Henry et al., 2013). However, results of a Dutch study (Nauta et al., 2000) involving nine experts identified the hatchery and the slaughter plant as critical steps in the transmission pathway of foodborne pathogens of poultry origin, and it was suggested that the application of effective control measures at those stages would give the best results. Experts of the current study estimated that broiler chicken meat contributes three times more to the human health burden attributed to Salmonella spp. than turkey meat. Based on a study conducted in Québec, Canada, the prevalence of Salmonella-positive carcasses was comparable between broiler chicken and turkey flocks at the time of slaughter (Arsenault et al., 2007). This difference might be explained by different marketing and consumption habits for the two products in Canada. Indeed, when attributing a level of risk to each commodity, the experts likely considered the domestic consumption aspect, which is $\sim 31.9$ and $4.2 \mathrm{~kg}$ per capita for chicken and turkey meat, respectively (Agriculture and AgriFood Canada, 2017). For egg products, layer birds and their production facilities were identified by the experts as critical elements contributing to the Salmonella spp. burden in humans, which is a well-defined picture all around the world (Gantois et al., 2009; Arnold et al., 2014; Denagamage et al., 2015).

The experts also estimated a RR value for 96 criteria that can impact the risk of Salmonella spp. in Canadian hatcheries. Within the inherent risk cluster, criteria related to incoming material and management practices, mixing eggs 
Table 6. Number of Respondents (N), Median Relative Risk Value (Q2), and 95\% Confidence INTERVAL FOR THE MEDIAN ESTIMATED by EXPERTS FOR ASSESSMENT CRITERIA RElated to the Risk Mitigation Factor Cluster (March 2017)

\begin{tabular}{|c|c|c|c|c|c|c|c|c|}
\hline \multirow{2}{*}{ Criteria } & & & \multicolumn{3}{|c|}{ First round } & \multicolumn{3}{|c|}{ Second round } \\
\hline & & & $\mathrm{n}$ & $Q 2$ & $95 \% C I$ & $\mathrm{n}$ & $Q 2$ & $95 \% C I$ \\
\hline \multicolumn{3}{|c|}{$\begin{array}{l}\text { 8. What would be the reduction in risk given to a hatchery operated under } \\
\text { a HACCP program compared with a hatchery that does not operate under } \\
\text { a HACCP program? }\end{array}$} & 13 & 2 & $1.5-3$ & 13 & 2 & $1.5-2$ \\
\hline \multicolumn{3}{|c|}{$\begin{array}{l}\text { 9. What would be the reduction in risk given to a hatchery that is HACCP } \\
\text { certified (by CFIA) compared with a hatchery that is not HACCP certified? }\end{array}$} & 12 & 2 & $1.5-3$ & 13 & 2 & $1.2-3$ \\
\hline \multirow[t]{4}{*}{$\begin{array}{l}\text { 10. Quality } \\
\text { assurance } \\
\text { program }\end{array}$} & (i) $\begin{array}{l}\mathrm{l} \\
\mathrm{v} \\
\mathrm{a} \\
\mathrm{p} \\
\mathrm{a} \\
\mathrm{a}\end{array}$ & $\begin{array}{l}\text { What would be the reduction in risk given to a hatchery } \\
\text { where } 1 \% \text { to } 25 \% \text { of the eggs originate from farms having } \\
\text { a quality assurance program (CHEQ program, NPIP } \\
\text { program, Turkey OFFSAP, PCP) in place compared with } \\
\text { a hatchery where all eggs originate from farms not having } \\
\text { a quality assurance program in place? }\end{array}$ & 12 & 1.2 & $1-1.5$ & 13 & 1.2 & $1.1-1.3$ \\
\hline & & $\begin{array}{l}\text { What would be the reduction in risk given to a hatchery } \\
\text { where } 26 \% \text { to } 50 \% \text { of the eggs originate from farms } \\
\text { having a quality assurance program (CHEQ program, } \\
\text { NPIP program, Turkey OFFSAP, PCP) in place compared } \\
\text { with a hatchery where all eggs originate from farms not } \\
\text { having a quality assurance program in place? }\end{array}$ & 12 & 1.5 & $1.2-2$ & 13 & 1.5 & $1.2-1.5$ \\
\hline & (iii) $\begin{array}{l}\mathrm{I} \\
\mathrm{b} \\
\mathrm{l} \\
\mathrm{I} \\
\mathrm{V} \\
\mathrm{l}\end{array}$ & $\begin{array}{l}\text { What would be the reduction in risk given to a hatchery } \\
\text { where } 51 \% \text { to } 75 \% \text { of the eggs originate from farms } \\
\text { having a quality assurance program (CHEQ program, } \\
\text { NPIP program, Turkey OFFSAP, PCP) in place compared } \\
\text { with a hatchery where all eggs originate from farms not } \\
\text { having a quality assurance program in place? }\end{array}$ & 12 & 1.65 & $1.5-2.5$ & 13 & 1.7 & $1.5-1.8$ \\
\hline & & $\begin{array}{l}\text { What would be the reduction in risk given to a hatchery } \\
\text { where } 76 \% \text { to } 100 \% \text { of the eggs originate from farms } \\
\text { having a quality assurance program (CHEQ program, } \\
\text { NPIP program, Turkey OFFSAP, PCP) in place compared } \\
\text { with a hatchery where all eggs originate from farms not } \\
\text { having a quality assurance program in place? }\end{array}$ & 12 & 2 & $2-3$ & 13 & 2 & $2-3$ \\
\hline \multicolumn{3}{|c|}{$\begin{array}{l}\text { 11. What would be the reduction in risk given to a hatchery requiring information } \\
\text { on the foodborne pathogen status of supplying flocks and that is using this } \\
\text { information to mitigate the risk (e.g., segregation of eggs) compared with a } \\
\text { hatchery for which eggs originate from farms with an unknown/uncertain } \\
\text { sanitary status and/or that is not taking any actions to manage the identified } \\
\text { risk? }\end{array}$} & 13 & 3 & $2-5$ & 13 & 3 & $2-4$ \\
\hline \multicolumn{3}{|c|}{$\begin{array}{l}\text { 12. What would be the reduction in risk given to a hatchery requiring information } \\
\text { on the vaccination history of supplying flocks and that is using this information } \\
\text { to mitigate the risk (e.g., segregation of eggs) compared with a hatchery for } \\
\text { which eggs originate from farms with an unknown/uncertain vaccination } \\
\text { history and/or that is not taking any actions to manage the identified risk? }\end{array}$} & 13 & 2 & $2-3$ & 13 & 2 & $2-3$ \\
\hline \multirow[t]{5}{*}{$\begin{array}{l}\text { 13. Egg } \\
\text { sanitation }\end{array}$} & & $\begin{array}{l}\text { What would be the reduction in risk given to a hatchery } \\
\text { where formaldehyde }(37 \%) \text { is administered using a CRI } \\
\text { method during hatching compared with a hatchery that } \\
\text { does not have any egg sanitation procedures? }\end{array}$ & 12 & 2 & $2-3$ & 12 & 2 & $2-3$ \\
\hline & & $\begin{array}{l}\text { What would be the reduction in risk given to a hatchery } \\
\text { where formaldehyde }(37 \%) \text { is administered multiple times } \\
\text { between transfer and hatching compared with a hatchery } \\
\text { that does not have any egg sanitation procedures? }\end{array}$ & 12 & 1.8 & $1.5-2$ & 12 & 1.8 & $1.5-2.5$ \\
\hline & & $\begin{array}{l}\text { What would be the reduction in risk given to a hatchery } \\
\text { where formaldehyde }(37 \%) \text { is administered only once at } \\
\text { the time of transfer compared with a hatchery that does } \\
\text { not have any egg sanitation procedures? }\end{array}$ & 12 & 1.25 & $1.2-1.5$ & 12 & 1.25 & $1.2-1.5$ \\
\hline & & $\begin{array}{l}\text { What would be the reduction in risk given to a hatchery } \\
\text { using fumigation of eggs during hatching instead of doing } \\
\text { no intervention? }\end{array}$ & 11 & 2 & $1.5-3$ & 11 & 2 & $1.5-3$ \\
\hline & & $\begin{array}{l}\text { What would be the reduction in risk given to a hatchery } \\
\text { fogging eggs in the incubator compared with a hatchery } \\
\text { not fogging eggs in the incubator? }\end{array}$ & 12 & 1.5 & $1.2-2$ & 12 & 1.5 & $1.2-2$ \\
\hline
\end{tabular}




\begin{tabular}{|c|c|c|c|c|c|c|c|c|}
\hline \multirow[b]{2}{*}{ Criteria } & & & \multicolumn{3}{|c|}{ First round } & \multicolumn{3}{|c|}{ Second round } \\
\hline & & & $\mathrm{n}$ & $Q 2$ & $95 \% C I$ & $\mathrm{n}$ & $Q 2$ & $95 \% C I$ \\
\hline \multirow[t]{7}{*}{$\begin{array}{l}\text { 14. Equipment } \\
\text { sanitation }\end{array}$} & (i) & $\begin{array}{l}\text { What would be the reduction in risk given to a hatchery } \\
\text { washing hatching trays under water pressure compared } \\
\text { with a hatchery not using pressure washing? }\end{array}$ & 13 & 1.5 & $1.2-2$ & 13 & 1.5 & $1.2-2$ \\
\hline & (ii) & $\begin{array}{l}\text { What would be the reduction in risk given to a hatchery in } \\
\text { which chick boxes are cleaned under water pressure jet } \\
\text { spray followed by a decontamination step compared with a } \\
\text { hatchery only using water pressure jet spray to clean chick } \\
\text { boxes (without any additional decontamination steps)? }\end{array}$ & 13 & 1.5 & $1.3-3$ & 13 & 1.5 & $1.3-3$ \\
\hline & (iii) & $\begin{array}{l}\text { What would be the reduction in risk given to a hatchery } \\
\text { fumigating the hatchers with formaldehyde after cleaning } \\
\text { and disinfection compared with a hatchery that does not } \\
\text { fumigate the hatchers with formaldehyde following } \\
\text { cleaning and disinfection? }\end{array}$ & 13 & 1.5 & $1.2-5$ & 13 & 1.5 & $1.2-4$ \\
\hline & (iv) & $\begin{array}{l}\text { What would be the reduction in risk given to a hatchery } \\
\text { that washes trays using washing machines (assuming the } \\
\text { machine is properly functioning) compared with a } \\
\text { hatchery that manually washes trays? }\end{array}$ & 13 & 1.3 & $1.2-1.5$ & 13 & 1.4 & $1.2-2$ \\
\hline & (v) & $\begin{array}{l}\text { What would be the reduction in risk given to a hatchery } \\
\text { using new cardboard trays or chick boxes (not reused) } \\
\text { compared with a hatchery that reuses cardboards trays or } \\
\text { chick boxes? }\end{array}$ & 13 & 2 & $1.5-4$ & 13 & 2 & $1.5-4$ \\
\hline & (vi) & $\begin{array}{l}\text { What would be the reduction in risk given to a hatchery } \\
\text { that meters the sanitizer concentration rather than } \\
\text { manually adding sanitizers? }\end{array}$ & 13 & 1.7 & $1.1-2$ & 13 & 1.7 & $1.4-2$ \\
\hline & (vii) & $\begin{array}{l}\text { What would be the reduction in risk given to a hatchery } \\
\text { that has practices to reduce egg breakage during handling } \\
\text { and processing compared with a hatchery that has no } \\
\text { procedure in place? }\end{array}$ & 13 & 1.8 & $1.2-2$ & 13 & 1.8 & $1.2-2$ \\
\hline \multirow[t]{2}{*}{ 15. Air sanitation } & (i) & $\begin{array}{l}\text { What would be the reduction in risk given to a hatchery } \\
\text { using air sanitation measures (e.g., filter changes, } \\
\text { ionization) compared with a hatchery that has no control } \\
\text { over air quality? }\end{array}$ & 13 & 1.5 & $1.2-3$ & 13 & 1.5 & $1.2-2$ \\
\hline & (ii) & $\begin{array}{l}\text { What would be the reduction in risk given to a hatchery } \\
\text { that has a method in place (e.g., ESCS, water spraying) to } \\
\text { reduce dust levels in hatching cabinets compared with a } \\
\text { hatchery that does not have procedures in place? }\end{array}$ & 13 & 1.5 & $1.2-1.7$ & 13 & 1.5 & $1.2-1.5$ \\
\hline \multicolumn{3}{|c|}{$\begin{array}{l}\text { 16. What would be the reduction in risk given to a hatchery conducting facility } \\
\text { sampling and bacterial sensitivity testing on these samples for disinfectant } \\
\text { turnover compared with a hatchery that arbitrarily selects the disinfectants } \\
\text { used in the facility? }\end{array}$} & 13 & 1.7 & $1.1-2.2$ & 13 & 1.7 & $1.1-2.2$ \\
\hline \multicolumn{3}{|c|}{$\begin{array}{l}\text { 17. What would be the reduction in risk given to a hatchery having a sampling } \\
\text { plan in place, beyond CFIA's requirements, to identify hazards, and that } \\
\text { includes trend analysis and action plan when triggers are identified? }\end{array}$} & 13 & 2 & $2-3$ & 13 & 2 & $2-3$ \\
\hline \multicolumn{3}{|c|}{$\begin{array}{l}\text { 18. What would be the reduction in risk given to a hatchery exporting chicks (e.g., } \\
\text { to the EU) compared with a hatchery not exporting chicks? }\end{array}$} & 13 & 1.5 & $1-3$ & 13 & 1.5 & $1-3$ \\
\hline \multicolumn{3}{|c|}{$\begin{array}{l}\text { 19. What would be the reduction in risk to a hatchery having quality control } \\
\text { measures for incoming eggs to identify hazards, and that includes trend } \\
\text { analysis and action plan when triggers are identified? }\end{array}$} & 13 & 2 & $1.7-3$ & 13 & 2 & $1.7-3$ \\
\hline \multicolumn{3}{|c|}{$\begin{array}{l}\text { 20. What would be the maximum reduction in risk given to a hatchery in which } \\
\text { risk mitigation measures are appropriately put in place for all of the } \\
\text { abovementioned risk mitigation factors? }\end{array}$} & 10 & 5.5 & $3-10$ & 12 & 6 & $5-10$ \\
\hline
\end{tabular}

CFIA, Canadian Food Inspection Agency; CHEQ, Canadian Hatching Egg Quality; CI, confidence interval; CRI, constant rate infusion; ESCS, Electrostatic Space Charge System; EU, European Union; HACCP, Hazard Analysis and Critical Control Point; NPIP, National Poultry Improvement Plan; OFFSAP, On-Farm Food Safety Assurance Program; PCP, Preventive Control Plan.

from different supplying breeder flocks in the same hatcher, frequently obtaining imported eggs from the spot market due to unexpected surge demand (i.e., unexpectedly importing incubation eggs from known and/or unknown sources to meet clients' needs), and hatching more than one species of poultry, were estimated to be the most important contributors to the overall inherent risk of a hatchery. In Canada, the poultry sector is subject to supply management, a system that matches the domestic production to the consumer demand across the country. When events affecting egg supply or hatchability happen, importing eggs with potentially unknown status is an alternate way for Canadian hatcheries to meet a demand that 
Table 7. Number of Respondents (N), Median Relative Risk Value (Q2), and 95\% Confidence Interval FOR the Median Estimated by EXPERTS FOR Assessment CRiteria Related

\begin{tabular}{|c|c|c|c|c|c|}
\hline \multirow[b]{2}{*}{ Criteria } & \multicolumn{3}{|c|}{ First round } & \multicolumn{2}{|c|}{ Second round } \\
\hline & $\mathrm{n}$ & $Q 2$ & $95 \% C I$ & $Q^{2}$ & $95 \% C I$ \\
\hline
\end{tabular}

21. What would be the increase in risk given to a hatchery if a governmental

$13 \quad 1.3 \quad 1.1-1.5 \quad 13 \quad 1.3 \quad 1.1-1.5$ inspector is doing an inspection of the hatchery's traceability and response program and notes a nonconformity that has a potential impact on food safety?

22. What would be the increase in risk given to a hatchery if while reviewing the last three governmental inspections (excluding the current) of the hatchery's traceability and response program, the inspector notes

(i) One nonconformity out of three that had a potential impact on food safety?

(ii) Two nonconformities out of three that had a potential impact on food safety?
(iii) Three nonconformities out of three that had a potential impact on food safety?

23. What would be the increase in risk given to a hatchery if a governmental inspector is doing an inspection of the hatchery's pest control program and notes: nonconformity that has a potential impact on food safety?

24. What would be the increase in risk given to a hatchery if while reviewing the last three governmental inspections (excluding the current) of

(i) One nonconformity out of three that had a potential impact on food safety? the hatchery's pest control program, the inspector notes

(ii) Two nonconformities out of three safety?
(iii) Three nonconformities out of three that had a potential impact on food safety?

25. What would be the increase in risk given to a hatchery if a governmental inspector is doing an inspection of the hatchery's general hygiene program and notes a nonconformity that has a potential impact on food safety?

26. What would be the increase in risk given to a hatchery if while reviewing the last three governmental inspections (excluding the current) of
131.6
$1.3-3$
$13 \quad 1.5 \quad 1.3-2$

the hatchery's general hygiene program, the inspector notes

27. What would be the increase in risk given to a hatchery if a governmental inspector is doing an inspection of the hatchery's sanitation program and notes a nonconformity that has a potential impact on food safety?

28. What would be the increase in risk given to a hatchery if while reviewing the last three governmental inspections (excluding the current) of the hatchery's sanitation program, the inspector notes (i) One nonconformity out of three that had a potential impact on food safety?

(ii) Two nonconformities out of three safety?
(iii) Three nonconformities out of three that had a potential impact on food safety?

(i) One nonconformity out of three $\quad \begin{array}{lllllll}13 & 1.8 & 1.3-2 & 13 & 1.8 & 1.5-2\end{array}$ that had a potential impact on food safety?
$13 \quad 1.5 \quad 1.1-2 \quad 13 \quad 1.5 \quad 1.1-2$

131.3

$1.1-2$

$13 \quad 1.5 \quad 1.1-1.6$ 
29. What would be the increase in risk given to a hatchery if a governmental n $\quad Q 2 \quad 95 \%$ CI $\quad$ n $Q 2 \quad 95 \% \quad C I$ inspector is doing an inspection of the hatchery's biosecurity program and notes a nonconformity that has a potential impact on food safety?

30. What would be the increase in risk given to a hatchery if while reviewing the last three governmental inspections (excluding the current) of the hatchery's biosecurity program, the inspector notes

(i) One nonconformity out of three that had a potential impact on food safety?

$\begin{array}{llllll}13 & 1.5 & 1.1-2 & 13 & 1.5 & 1.1-2\end{array}$

$13 \quad 1.3 \quad 1.1-2 \quad 13 \quad 1.3 \quad 1.1-1.7$

$$
\text { safety? }
$$

(ii) Two nonconformities out of three that had a potential impact on food safety?
(iii) Three nonconformities out of three that had a potential impact on food safety?

31. What would be the increase in risk given to a hatchery if a governmental inspector is doing an inspection of the hatchery's employee training program and notes a nonconformity that has a potential impact on food safety?

32. What would be the increase in risk given to a hatchery if while reviewing the last three governmental inspections (excluding the current) of

(i) One nonconformity out of three that had a potential impact on food safety? the hatchery's employee training program, the inspector notes

(ii) Two nonconformities out of three that had a potential impact on food safety?

(iii) Three nonconformities out of three that had a potential impact on food safety?

33. What would be the increase in risk given to a hatchery if a governmental inspector is doing an inspection of the hatchery's building structure and maintenance program and notes a nonconformity that has a potential impact on food safety?

34. What would be the increase in risk given to a hatchery if while reviewing the last three governmental inspections (excluding the current) of the hatchery's building structure and maintenance program, the inspector notes

(i) One nonconformity out of three that had a potential impact on food safety?

$\begin{array}{llllll}13 & 1.8 & 1.2-3 & 13 & 1.7 & 1.2-2\end{array}$

$13 \quad 1.2 \quad 1.1-1.5 \quad 13 \quad 1.2 \quad 1.1-1.5$

$\begin{array}{llllll}13 & 1.2 & 1-1.5 & 13 & 1.2 & 1-1.5\end{array}$

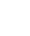

$\begin{array}{llllll}13 & 2 & 1.3-4 & 13 & 2 & 1.3-3\end{array}$

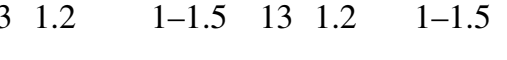

$\begin{array}{llllll}13 & 1.3 & 1.2-2 & 13 & 1.3 & 1.2-2\end{array}$

$\begin{array}{llllll}13 & 1.5 & 1.3-3 & 13 & 1.5 & 1.3-3\end{array}$

$\begin{array}{llllll}13 & 1.5 & 1.2-2 & 13 & 1.5 & 1.2-1.7\end{array}$

$13 \quad 1.5 \quad 1.1-1.6 \quad 13 \quad 1.5 \quad 1.1-1.6$
(ii) Two nonconformities out of three $\begin{array}{llllll}13 & 1.8 & 1.3-2 & 13 & 1.8 & 1.3-2\end{array}$ that had a potential impact on food safety?
(iii) Three nonconformities out of three $\begin{array}{lllllll}13 & 2 & 1.4-3 & 13 & 2 & 1.4-3\end{array}$ that had a potential impact on food safety?

35. What would be the increase in risk given to a hatchery if a governmental $\quad \begin{array}{llllll}13 & 1.5 & 1.1-2 & 13 & 1.4 & 1.1-1.6\end{array}$ inspector is doing an inspection of the hatchery's transportation, receiving, shipping, and storage program and notes a nonconformity that has a potential impact on food safety?

36. What would be the increase in risk given to a hatchery if while reviewing the last three governmental inspections (excluding the current) of

(i) One nonconformity out of three that had a potential impact on food $13 \quad 1.4 \quad 1.1-1.5 \quad 13 \quad 1.4 \quad 1.1-1.5$ safety? the hatchery's transportation, receiving, shipping, and storage program, the inspector notes 


$\overline{\mathrm{n}} \quad Q_{2} \quad 95 \% C I \quad \mathrm{n} \quad Q 2 \quad 95 \% C I$

(ii) Two nonconformities out of three

$\begin{array}{llll}1.2-2.5 & 13 & 1.6 & 1.2-2\end{array}$ that had a potential impact on food safety?

(iii) Three nonconformities out of three $\begin{array}{llllll}13 & 1.9 & 1.3-3 & 13 & 1.9 & 1.3-3\end{array}$ that had a potential impact on food safety?

37. What would be the increase in risk given to a hatchery if a governmental inspector is doing an inspection of the hatchery's control of critical control points program and notes a nonconformity that has a potential impact on food safety?

38. What would be the increase in risk given to a hatchery if while reviewing the last three governmental inspections (excluding the current) of the hatchery's control of critical control points program, the inspector notes

(i) One nonconformity out of three that had a potential impact on food safety?

$132 \quad 1.5-3 \quad 13 \quad 2 \quad 1.6-2.5$

(ii) Two nonconformities out of three
that had a potential impact on food 13 safety?

(iii) Three nonconformities out of three that had a potential impact on food safety?

39. What would be the increase in risk given to a hatchery if a governmental inspector is doing an inspection of the hatchery's equipment maintenance and calibration program and notes a nonconformity that has a potential impact on food safety?

40. What would be the increase in risk given to a hatchery if while reviewing the last three governmental inspections (excluding the current) of the hatchery's equipment maintenance and calibration program, the inspector notes

(i) One nonconformity out of three that had a potential impact on food safety?

41. What would be the increase in risk given to a hatchery that has experienced any of these Enforcement Actions in the past 2 years

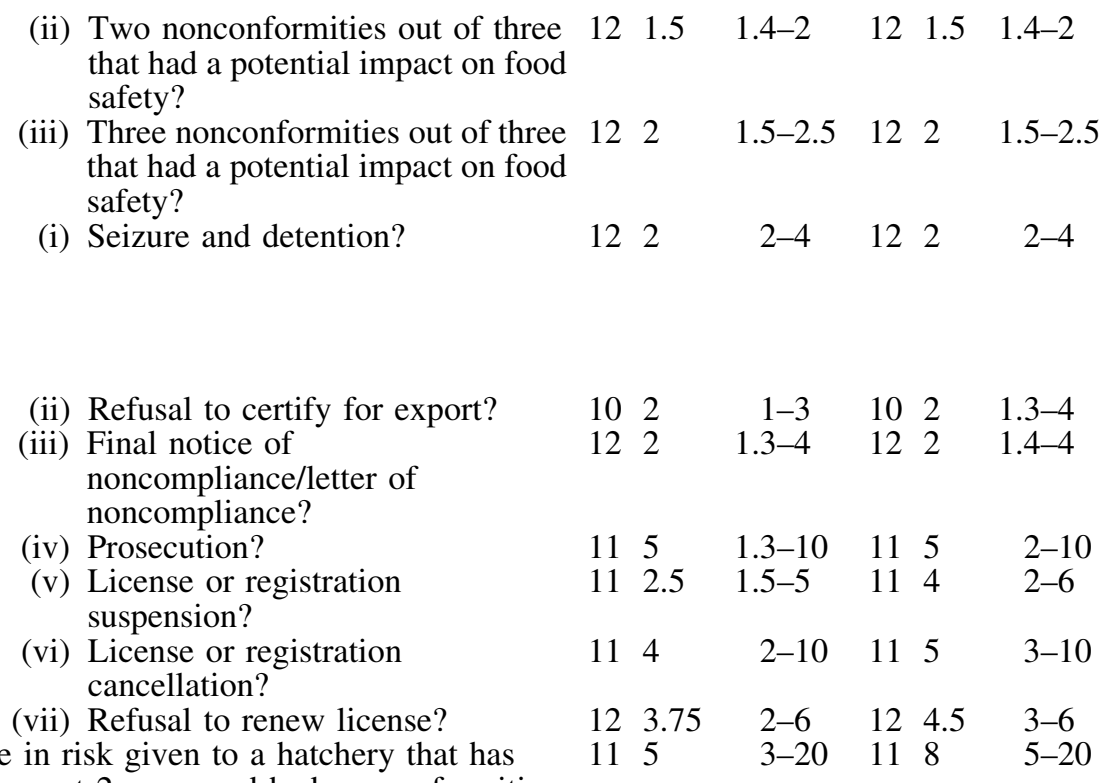

42. What would be the maximum increase in risk given to a hatchery that has experienced enforcement actions in the past 2 years and had nonconformities with a potential impact on food safety in all four governmental inspections related to Compliance Factors (traceability and response program, pest control program, general hygiene program, sanitation program, biosecurity program, employee training program, building structure and maintenance program, transportation, receiving, shipping, and storage program, control of critical control points program, equipment maintenance, and calibration program)?

CI, confidence interval. 
Table 8. Number of Respondents ( $N$ ), Median Relative Risk Value (Q2), and 95\% Confidence Interval for the Median Estimated by EXPERTs for Assessment Criteria Related to the Compliance Factor Cluster (SePtember 2017)

\begin{tabular}{|c|c|c|c|c|c|c|c|}
\hline \multirow[b]{2}{*}{ Criteria } & & \multicolumn{3}{|c|}{ First round } & \multicolumn{3}{|c|}{ Second round } \\
\hline & & $\mathrm{n}$ & $Q 2$ & $95 \% C I$ & $\mathrm{n}$ & $Q 2$ & $95 \% C I$ \\
\hline \multirow{3}{*}{$\begin{array}{l}\text { 43. What would be the increase in risk given } \\
\text { to a hatchery for which fluff samples } \\
\text { tested positive for Salmonella spp. (that } \\
\text { have an impact on food safety }{ }^{\mathrm{a}} \text { ) }\end{array}$} & $\begin{array}{l}\text { (i) In } 1 \% \text { to } 10 \% \text { of all samples tested in } \\
\text { the past year? }\end{array}$ & 12 & 1.5 & $1.3-2$ & 12 & 1.5 & $1.5-2.5$ \\
\hline & $\begin{array}{l}\text { (ii) In } 11 \% \text { to } 50 \% \text { of all samples tested } \\
\text { in the past year? }\end{array}$ & 12 & 2.5 & $1.8-5$ & 12 & 2.75 & $2-5$ \\
\hline & $\begin{array}{l}\text { (iii) In more than } 50 \% \text { of all samples } \\
\text { tested in the past year? }\end{array}$ & 12 & 4.5 & $2.5-10$ & 12 & 5 & $4-10$ \\
\hline \multicolumn{2}{|c|}{$\begin{array}{l}\text { 44. What would be the increase in risk given to a hatchery if a governmental inspector is } \\
\text { doing an inspection of the hatchery's incoming supplies program and notes a } \\
\text { nonconformity that has a potential impact on food safety? }\end{array}$} & 12 & 1.6 & $1.3-2$ & 12 & 1.6 & $1.3-2$ \\
\hline \multirow{3}{*}{$\begin{array}{l}\text { 45. What would be the increase in risk given } \\
\text { to a hatchery if while reviewing the last } \\
\text { three governmental inspections (excluding } \\
\text { the current) of the hatchery's incoming } \\
\text { supplies program, the inspector notes }\end{array}$} & $\begin{array}{l}\text { (i) One nonconformity out of three that } \\
\text { had a potential impact on food } \\
\text { safety? }\end{array}$ & 12 & 1.5 & $1.2-1.5$ & 12 & 1.5 & $1.2-1.5$ \\
\hline & $\begin{array}{l}\text { (ii) Two nonconformities out of three } \\
\text { that had a potential impact on food } \\
\text { safety? }\end{array}$ & 12 & 1.85 & $1.5-2.4$ & 12 & 1.85 & $1.5-2.4$ \\
\hline & $\begin{array}{l}\text { (iii) Three nonconformities out of three } \\
\text { that had a potential impact on food } \\
\text { safety? }\end{array}$ & 12 & 2.35 & $2-3$ & 12 & 2.35 & $2-3$ \\
\hline \multicolumn{2}{|c|}{$\begin{array}{l}\text { 46. What would be the increase in risk given to a hatchery if a governmental inspector is } \\
\text { doing an inspection of the hatchery's premises and surroundings program and notes a } \\
\text { nonconformity that has a potential impact on food safety? }\end{array}$} & 12 & 1.5 & $1.2-1.5$ & 12 & 1.5 & $1.2-1.5$ \\
\hline \multirow{3}{*}{$\begin{array}{l}\text { 47. What would be the increase in risk given } \\
\text { to a hatchery if while reviewing the last } \\
\text { three governmental inspections (excluding } \\
\text { the current) of the hatchery's premises and } \\
\text { surroundings program, the inspector notes }\end{array}$} & $\begin{array}{l}\text { (i) One nonconformity out of three that } \\
\text { had a potential impact on food } \\
\text { safety? }\end{array}$ & 12 & 1.15 & $1.1-1.4$ & 12 & 1.2 & $1.1-1.4$ \\
\hline & $\begin{array}{l}\text { (ii) Two nonconformities out of three } \\
\text { that had a potential impact on food } \\
\text { safety? }\end{array}$ & 12 & 1.5 & $1.3-1.5$ & 12 & 1.5 & $1.5-1.5$ \\
\hline & $\begin{array}{l}\text { (iii) Three nonconformities out of three } \\
\text { that had a potential impact on food } \\
\text { safety? }\end{array}$ & 12 & 1.85 & $1.5-2$ & 12 & 1.85 & $1.5-2$ \\
\hline \multicolumn{2}{|c|}{$\begin{array}{l}\text { 48. What would be the increase in risk given to a hatchery if a governmental inspector is } \\
\text { doing an inspection of the hatchery's waste control program and notes a } \\
\text { nonconformity that has a potential impact on food safety? }\end{array}$} & 12 & 1.5 & $1.3-1.5$ & 12 & 1.5 & $1.3-1.5$ \\
\hline \multirow{3}{*}{$\begin{array}{l}\text { 49. What would be the increase in risk given } \\
\text { to a hatchery if while reviewing the last } \\
\text { three governmental inspections (excluding } \\
\text { the current) of the hatchery's waste } \\
\text { control program, the inspector notes }\end{array}$} & $\begin{array}{l}\text { (i) One nonconformity out of three that } \\
\text { had a potential impact on food } \\
\text { safety? }\end{array}$ & 12 & 1.3 & $1.2-1.5$ & 12 & 1.35 & $1.2-1.5$ \\
\hline & $\begin{array}{l}\text { (ii) Two nonconformities out of three } \\
\text { that had a potential impact on food } \\
\text { safety? }\end{array}$ & 12 & 1.5 & $1.5-1.8$ & 12 & 1.6 & $1.5-2$ \\
\hline & $\begin{array}{l}\text { (iii) Three nonconformities out of three } \\
\text { that had a potential impact on food } \\
\text { safety? }\end{array}$ & 12 & 2 & $1.6-2.4$ & 12 & 2 & $1.7-2.5$ \\
\hline \multicolumn{2}{|c|}{$\begin{array}{l}\text { 50. What would be the maximum increase in risk given to a hatchery that has experienced } \\
\text { enforcement actions in the past } 2 \text { years, had nonconformities with a potential impact on } \\
\text { food safety in all four governmental inspections related to Compliance Factors } \\
\text { (traceability and response, pest control, general hygiene, sanitation, biosecurity, } \\
\text { employee training, building structure and maintenance, control of critical control } \\
\text { points, equipment maintenance and calibration, incoming supplies, premises and } \\
\text { surroundings, waste control, transportation, receiving, shipping, and storage) and had } \\
\text { fluff samples positive for Salmonella spp. (that have an impact on food safety) in more } \\
\text { than } 50 \% \text { of all samples tested in the past year? }\end{array}$} & 12 & 10 & $4-20$ & 12 & 10 & $5-20$ \\
\hline
\end{tabular}

${ }^{a}$ Salmonella spp. including among others Salmonella Enteritidis, Salmonella Typhimurium, and Salmonella Heidelberg, but excluding Salmonella Gallinarum and Salmonella Pullorum.

${ }^{\mathrm{b}}$ Incoming products refer to the eggs and chicks received at the establishment (including those imported) as well as the drugs/vaccines administered at the hatchery. Packaging materials and chemicals are evaluated by other control programs and are therefore not covered in the incoming products control program.

CI, confidence interval. 
Table 9. Number of Assessment Criteria Categorized According to the Median Relative Risk Values Estimated BY EXPERTS AND Clusters

\begin{tabular}{lcccc}
\hline & \multicolumn{3}{c}{ Number of criteria with a relative risk of } & Total \\
\cline { 2 - 4 } Cluster & $<2$ & 2 to 3 & $>3$ & $8(8.3 \%)$ \\
Inherent risk factors & 5 & 3 & 0 & $26(27.1 \%)$ \\
Mitigation factors & 16 & 10 & 0 & $62(64.6 \%)$ \\
Compliance factors & 39 & $31(32.3 \%)$ & 5 & 96 \\
Total & $60(62.5 \%)$ & $5.2 \%)$ & 96 \\
\hline
\end{tabular}

cannot be fulfilled domestically. Volkova et al. (2011) showed that a higher number of supplying parent flocks was associated with a significantly higher probability of detecting Salmonella spp. in the gastrointestinal tract of day-old broilers delivered to grow-out farms. The fact that the Salmonella spp. status of some supplying flocks might be unknown probably prompted experts to give more weight to this criterion. Operational features of a hatchery, such as having fixed incubator trolleys or using an evaporative cooling ventilation system, were considered by the experts as affecting a hatchery's food safety risk to a lesser extent. In Volkova et al. (2011), evaporative cooling increased the odds of detecting Salmonella spp. by more than four times when compared with an air conditioning system. However, this risk factor was not retained in their final models.

Within the risk mitigation cluster, requiring information on the foodborne pathogen status of the supplying breeder flocks and using this information to mitigate the risk was considered by experts of the current elicitation to contribute to the greatest reduction in the food safety risk of a hatchery (threefold reduction). It has been reported that a high Salmonella spp. prevalence in a specific breeder flock is correlated with a higher prevalence of Salmonella spp.-positive eggs laid by those birds, and more specifically, with a higher contamination rate of the eggshells (Arnold et al., 2014). This emphasizes the importance of monitoring programs for supplying breeder flocks when evaluating the risk that they may pose to a hatchery. For the current risk assessment model, an increase in the inherent risk of a hatchery would be offset by the reduction in risk for requiring and utilizing the information on the foodborne pathogen status of the supply flocks.

From the criteria that were estimated to contribute to a twofold reduction in risk, having a sampling plan to identify hazards, coupled with a trend analysis and an action plan when triggers are identified, was determined by the experts as an important mitigation measure, and is in agreement with previously published literature (Samberg and Meroz, 1995; USDA, 2014). Similarly, the implementation of a quality assurance program at the hatchery level, such as Hazard Analysis and Critical Control Point (HACCP), was recognized to mitigate the food safety risk. Such programs are key elements for ensuring the quality of the end-product (birds), although they do not specifically tackle foodborne pathogens along this production chain (Billy and Wachsmuth, 1997).

Experts also estimated a twofold reduction of risk to certain methods of egg sanitation during hatching, including the administration of formaldehyde (37\%) using a constant rate infusion method and a fumigation approach. It is generally accepted that hatching is the critical point among all of the activities taking place in a hatchery for the control of Salmonella spp., and it is recognized that egg sanitation positively impacts the overall hygiene status of a hatchery (Samberg and Meroz, 1995; Bailey et al., 1996; MuellerDoblies et al., 2013; USDA, 2014; Gottselig et al., 2016). Indeed, it is well known that bacterial contamination will increase in the hatcher as hatch nears completion due to the increasing density of hatchlings in a confined space and the increasing amount of fluff disseminated throughout the hatcher by air movement (Kim and Kim, 2010). Research has shown that hatchers and their related ventilation system and equipment are more likely to be contaminated than all other areas or devices in a hatchery (Kim and Kim, 2010; MuellerDoblies et al., 2013). The hatching room has also been identified as a major source of Salmonella spp. contamination in a hatchery (Chao et al., 2007; Kim and Kim, 2010). However, no fumigation program should be used to replace cleanliness (Wright and Epps, 1958). Experts also identified the use of new cardboard trays or chick boxes (not reused) as an important mitigation approach.

All of the experts agreed that compliance with control measures and regulatory requirements imposed by the CFIA influenced the level of risk. Indeed, experts considered a hatchery to represent a risk for food safety that can be up to 10 times higher when all measures pertaining to compliance were not implemented as requested. Noncompliance related to process control (critical control points) and sanitation programs received the highest increase in risk among all of the Preventive Control Plan sub-elements (CFIA, 2019b). The role of sanitation in controlling foodborne pathogen contamination has been clearly demonstrated (Christensen et al., 1997). In addition, criteria related to enforcement actions by the CFIA were considered by the experts to have the greatest contribution to increasing the global risk.

Experts consulted during the elicitation process all agreed that the risk represented by a hatchery was greatly increased if Salmonella spp. was identified through monitoring programs, such as the CFIA's regulatory fluff sampling program. The detection of Salmonellae indicates a potential defect in the food safety management system and should trigger appropriate prevention and control activities, as it has been clearly shown that the implementation of control measures at the hatchery level after early identification of contamination can prevent further transmission of Salmonella spp. (White et al., 1997; Sivaramalingam et al., 2013).

It should be emphasized that the objective of this study was to elicit expert opinion to estimate the RR of each criterion rather than determine whether the RR values differed significantly. Confidence intervals were used to quantify the degree of uncertainty around each median. Although some of 
the criteria were deemed by the experts to be more important than others, the relative importance of each criterion should be interpreted with care, as confidence intervals sometimes overlapped. Expert elicitations can be used as a first line of evidence, in the absence of other data, to assess the importance and weighting of criteria. However, inherent limitations of this type of study need to be considered and should trigger further studies to confirm the importance of these criteria.

\section{Conclusions}

This study aimed to quantify the assessment criteria that will be included in the ERA-H model, based on their impact on human health, with a specific focus on Salmonella spp. The median RR value assigned to each criterion and cluster during the second round of the expert elicitations will be used in this new model to assess the food safety risk of Canadian hatcheries under CFIA's jurisdiction to judiciously allocate inspection resources for the protection of public health.

\section{Acknowledgments}

This study was made possible through the help and support from CFIA. The research team also acknowledges each expert who generously participated in this process.

\section{Disclosure Statement}

No competing financial interests exist.

\section{Funding Information}

This study was funded by the Canadian Food Inspection Agency under the initiative 'Improve Food Safety for Canadians'.

\section{References}

Agriculture and Agri-Food Canada (AAFC). 2017. Canada's poultry and egg industry profile. Available at: http://www.agr .gc.ca/eng/industry-markets-and-trade/statistics-and-marketinformation/by-product-sector/poultry-and-egg-sector/poultryand-egg-market-information/industry-profile/?id=1384971854389 accessed September 1, 2019.

Arnold ME, Martelli F, McLaren I, Davies RH. Estimation of the rate of egg contamination from Salmonella-infected chickens. Zoonoses Public Health 2014;61:18-27.

Arsenault J, Letellier A, Quessy S, Normand V, Boulianne M. Prevalence and risk factors for Salmonella spp. and Campylobacter spp. caecal colonization in broiler chicken and turkey flocks slaughtered in Québec, Canada. Prev Vet Med 2007;81:250-264.

Bailey JS, Buhr RJ, Cox NA, Berrang ME. Effect of hatching cabinet sanitation treatments on Salmonella cross-contamination and hatchability of broiler eggs. Poult Sci 1996;75:191-196.

Benjamini Y, Hochberg Y. Controlling the false discovery rate: A practical and powerful approach to multiple testing. J R Stat Soc Series B Stat Methodol 1995;57:289-300.

Billy TJ, Wachsmuth IK. Hazard analysis and critical control point systems in the United States Department of Agriculture regulatory policy. Rev Sci Tech 1997;16:342-348.

Bonett DG. Confidence interval for a coefficient of quartile variation. Comput Stat Data Anal 2006;50:2953-2957.
Bucher O, Fazil A, Rajic A, Farrar A, Wills R, McEwen SA. Evaluating interventions against Salmonella in broiler chickens: Applying synthesis research in support of quantitative exposure assessment. Epidemiol Infect 2012;140: 925-945.

Bulmer MG. Principles of Statistics. Mineola, NY: Dover Publications, 1979.

Butler AJ, Pintar KDM, Thomas MK. Estimating the relative role of various subcategories of food, water, and animal contact transmission of 28 enteric diseases in Canada. Foodborne Pathog Dis 2016;13:57-64.

Butler AJ, Thomas MK, Pintar KDM. Expert elicitation as a means to attribute 28 enteric pathogens to foodborne, waterborne, animal contact, and person-to-person transmission routes in Canada. Foodborne Pathog Dis 2015;12:335-344.

Canadian Food Inspection Agency (CFIA). 2019a. Establishmentbased Risk Assessment models. Available at: https://www .inspection.gc.ca/about-the-cfia/strategic-priorities/era-models/ eng/1564406870713/1564406870963 accessed September 1, 2019.

Canadian Food Inspection Agency (CFIA). 2019b. Standard Inspection Procedure (SIP) overview. Available at: https:// inspection.gc.ca/food/compliance-continuum/guidance-forinspectors/sip/overview/eng/1537319653853/1537319724052 accessed September 1, 2019.

Chao MR, Hsien CH, Yeh CM, Chou SJ, Chu C, Su YC, Yu CY. Assessing the prevalence of Salmonella enterica in poultry hatcheries by using hatched eggshell membranes. Poult Sci 2007;86:1651-1655.

Christensen JP, Brown DJ, Madsen M, Olsen JE, Bisgaard M. Hatchery-borne Salmonella enterica serovar Tennessee infections in broilers. Avian Pathol 1997;26:155-168.

Delbecq AL, Van de Ven AH, Gustafson DH. Group Techniques for Program Planning: A Guide to Nominal and Delphi Processes. Glenview, IL: Scott, Foresman and Co, 1975. Available at: https://sites.google.com/a/umn.edu/avandeven/ publications/books/group-techniques-for-program-planning accessed September 1, 2019.

Denagamage T, Jayarao B, Patterson P, Wallner-Pendleton E, Kariyawasam S. Risk factors associated with Salmonella in laying hen farms: Systematic review of observational studies. Avian Dis 2015;59:291-302.

Gantois I, Ducatelle R, Pasmans F, Haesebrouck F, Gast R, Humphrey TJ, Immerseel FV. Mechanisms of egg contamination by Salmonella enteritidis. FEMS Microbiol Rev 2009; 33:718-738.

Gottselig SM, Dunn-Horrocks SL, Woodring KS, Coufal CD, Duong T. Advanced oxidation process sanitization of eggshell surfaces. Poult Sci 2016:95:1356-1362.

Havelaar AH, Haagsma JA, Mangen MJJ, Kemmeren JM, Verhoef LPB, Vijgen SMC, Wilson M, Friesema IHM, Kortbeek LM, van Duynhoven YTHP, van Pelt W. Disease burden of foodborne pathogens in the Netherlands, 2009. Int J Food Microbiol 2012;156:231-238.

Henry I, Granier S, Courtillon C, Lalande F, Chemaly M, Salvat G, Cardinale E. Salmonella enterica subsp enterica isolated from chicken carcasses and environment at slaughter in Reunion Island: Prevalence, genetic characterization and antibiotic susceptibility. Trop Anim Health Prod 2013;45:317-326.

Heyndrickx M, Vandekerchove D, Herman L, Rollier I, Grijspeerdt K, De Zutter L. Routes for Salmonella contamination of poultry meat: Epidemiological study from hatchery to slaughterhouse. Epidemiol Infect 2002;129:253-265. 
Hogg RV, Tanis EA. Probability and Statistical Inference, 8th edition. Upper Saddle River, NJ: Pearson Education, Inc., 2010.

Hollander M, Wolfe DA. Nonparametric Statistical Methods, 2nd edition. New York, NY: John Wiley \& Sons, Inc., 1973.

Kim JH, Kim KS. Hatchery hygiene evaluation by microbiological examination of hatchery samples. Poult Sci 2010;89: 1389-1398.

Mueller-Doblies D, Clouting C, Davies RH. Investigations of the distribution and persistence of SALMONELLA and ciprofloxacin-resistant Escherichia coli in turkey hatcheries in the UK. Zoonoses Public Health 2013;60:296-303.

Namata H, Welby S, Aerts M, Faes C, Abrahantes JC, Imberechts $\mathrm{H}$, Vermeersch $\mathrm{K}$, Hooyberghs J, Méroc E, Mintiens $\mathrm{K}$. Identification of risk factors for the prevalence and persistence of Salmonella in Belgian broiler chicken flocks. Prev Vet Med 2009;90:211-222.

Nauta MJ, Van de Giessen AW, Henken AM. A model for evaluating intervention strategies to control Salmonella in the poultry meat production chain. Epidemiol Infect 2000;124: 365-373.

Racicot M, Comeau G, Tremblay A, Quessy S, Cereno T, Charron-Langlois M, Venne D, Hébert G, Vaillancourt JP, Fravalo P, Ouckama R, Mitevski D, Guerin MT, Agunos A, DeWinter L, Catford A, Mackay A, Gaucher ML. Identification and selection of food safety-related risk factors to be included in the Canadian Food Inspection Agency's Establishment-based Risk Assessment model for Hatcheries. Zoonoses Public Health 2019;1-11.

Samberg Y, Meroz M. Application of disinfectants in poultry hatcheries. Rev Sci Tech 1995;14:365-380.

Sivaramalingam T, Pearl DL, McEwen SA, Ojkic D, Guerin MT. A temporal study of Salmonella serovars from fluff samples from poultry breeder hatcheries in Ontario between 1998 and 2008. Can J Vet Res 2013;77:12-23.

Thomas MK, Murray R, Flockhart L, Pintar K, Pollari F, Fazil A, Nesbitt A, Marshall B. Estimates of the burden of foodborne illness in Canada for 30 specified pathogens and unspecified agents, circa 2006. Foodborne Pathog Dis 2013;10: 639-648.

U.S. Department of Agriculture (USDA). Best Management Practices Handbook. A Guide to the Mitigation of Salmonella Contamination at Poultry Hatcheries. Conyers, GA, 2014. Available at: https://www.poultryimprovement.org/documents/ BestManagementPracticesHatcheries.pdf accessed September $1,2019$.

Volkova VV, Bailey RH, Hubbard SA, Magee DL, Byrd JA, Robert WW. Risk factors associated with Salmonella status of broiler flocks delivered to grow-out farms. Zoonoses Public Health 2011;58:284-298.

White PL, Baker AR, James WO. Strategies to control Salmonella and Campylobacter in raw poultry products. Rev Sci Tech 1997; 16:525-541.

Wright ML, Epps NA. Hatchery sanitation. Can J Comp Med Vet Sci 1958;22:62-66.

Address correspondence to:

Manon Racicot, DVM, PhD

Canadian Food Inspection Agency 3200 Sicotte

St-Hyacinthe J2S $2 M 2$

Québec

Canada

E-mail: manon.racicot@canada.ca 


\section{Appendix}

Criterion 1

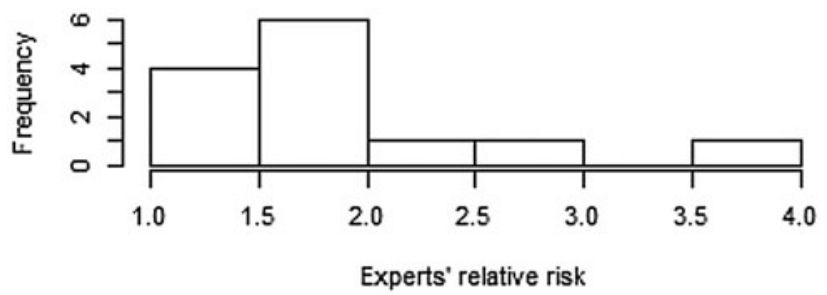

Criterion 2b

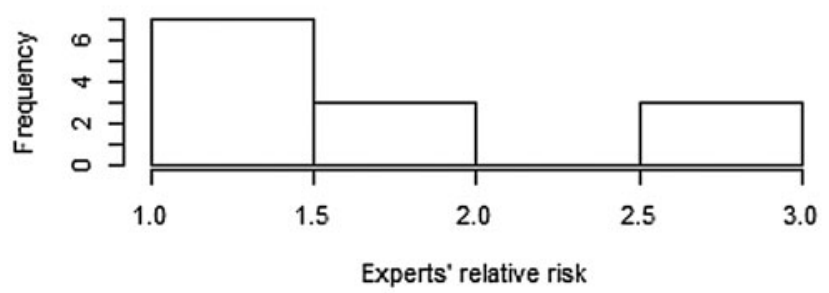

Criterion 3

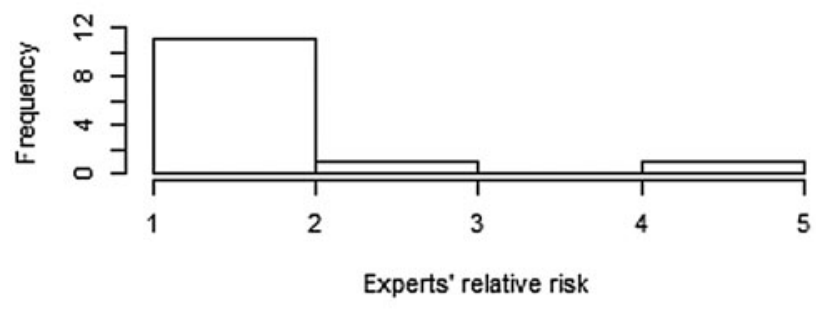

Criterion 5

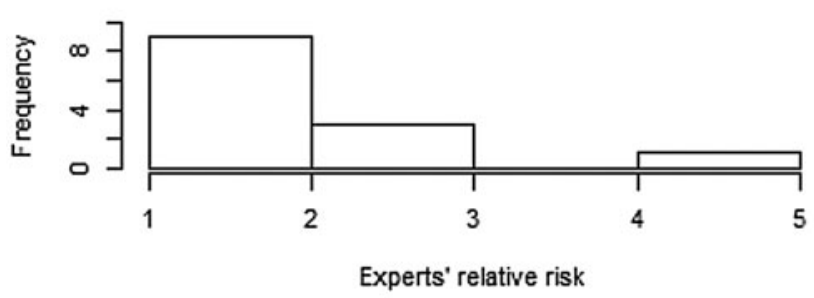

Criterion 7-cluster

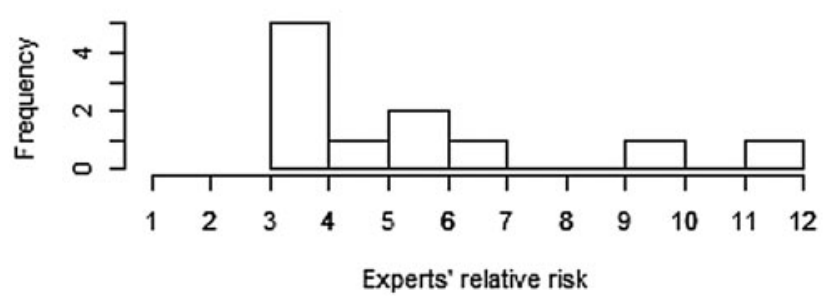

Criterion 2a

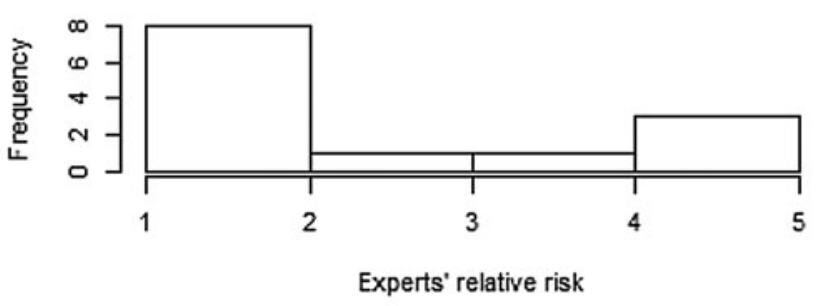

Criterion 2c

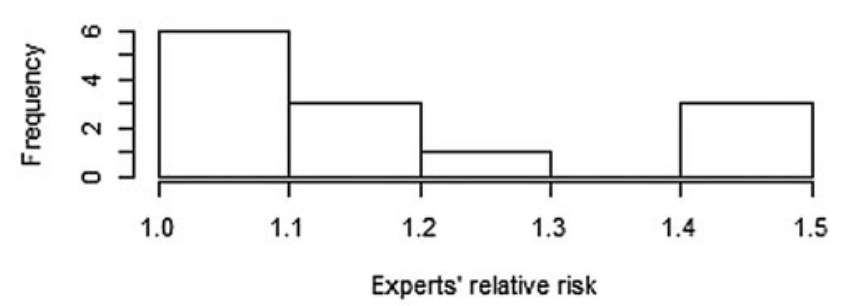

Criterion 4

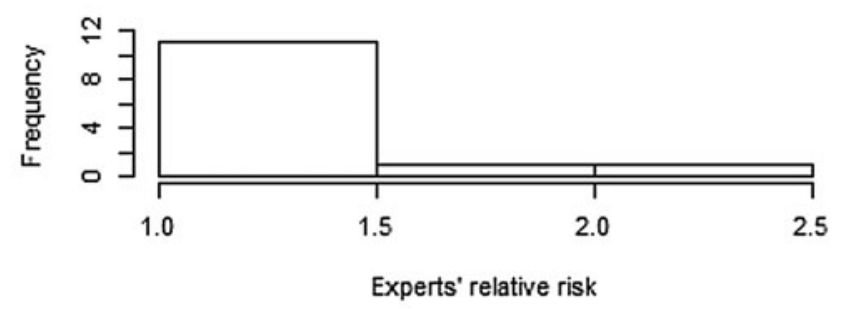

Criterion 6

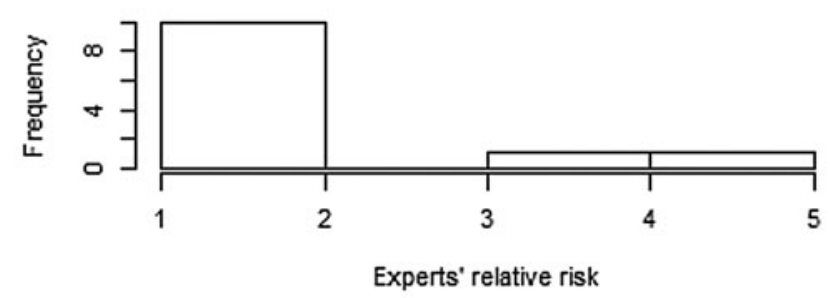

Criterion 8

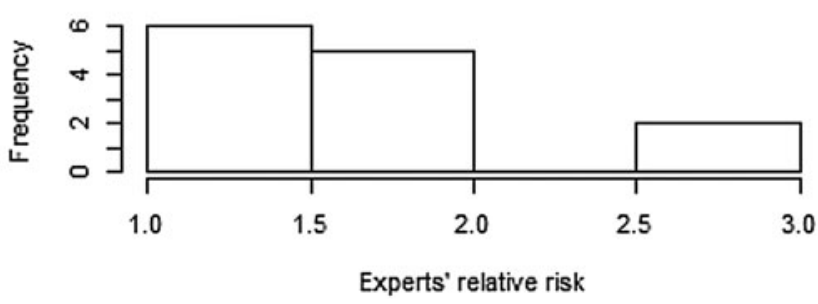

APPENDIX FIG. A1. Histograms of expert's relative risks for each criterion and cluster as per Tables 5 to 8 . 
Criterion 9

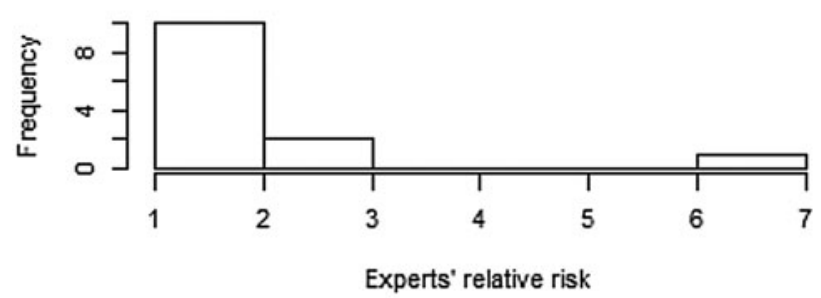

Criterion 10b

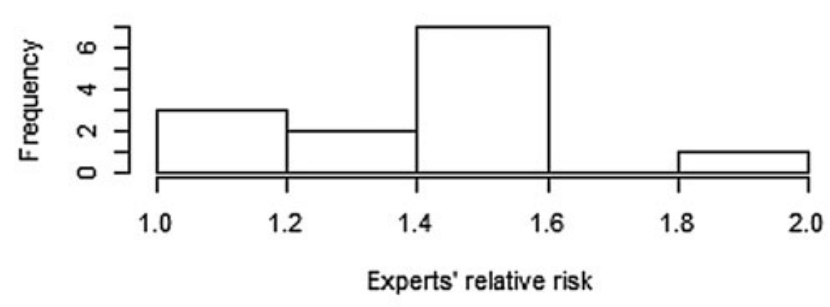

Criterion 10d

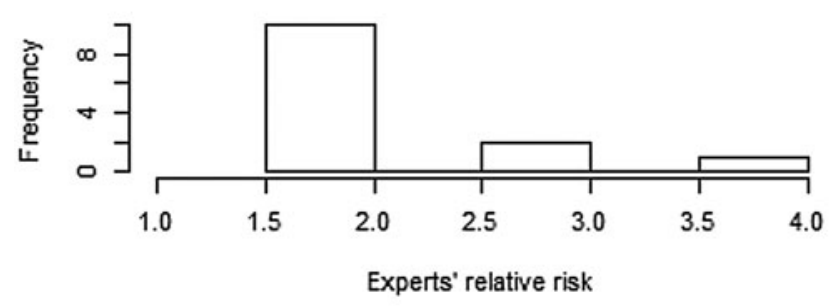

Criterion 12

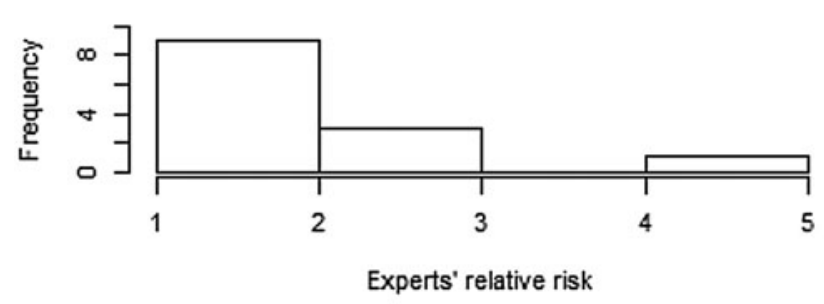

Criterion 13b

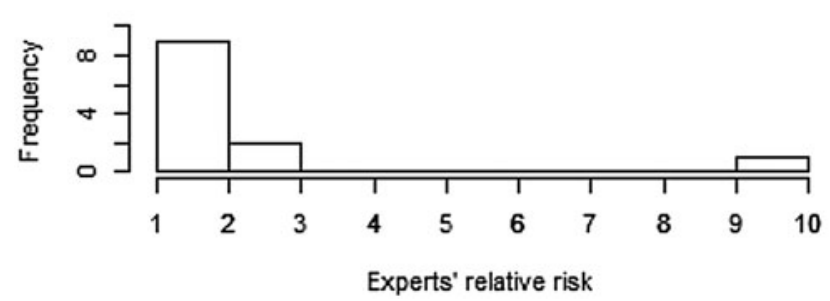

Criterion 10a

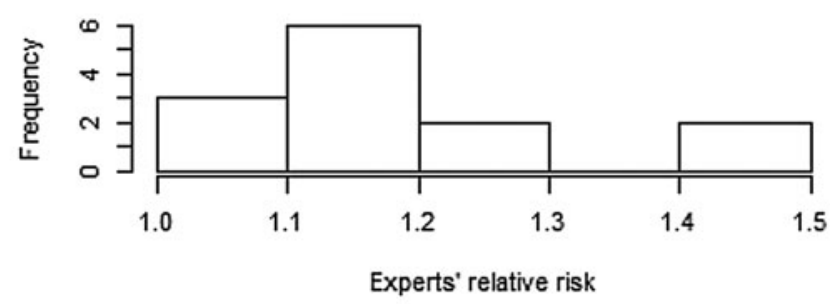

Criterion 10c

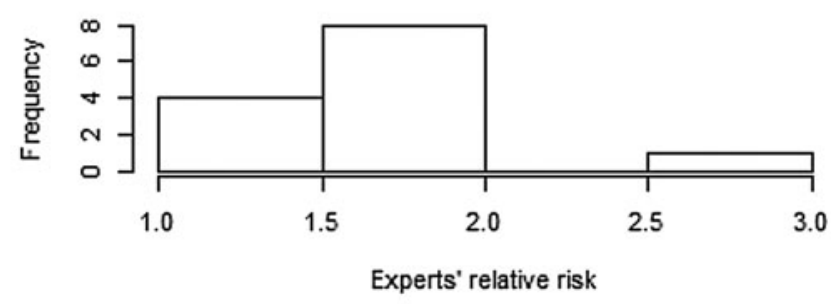

Criterion 11

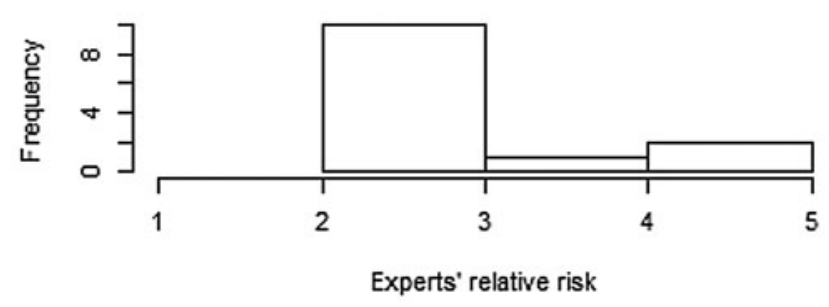

Criterion 13a

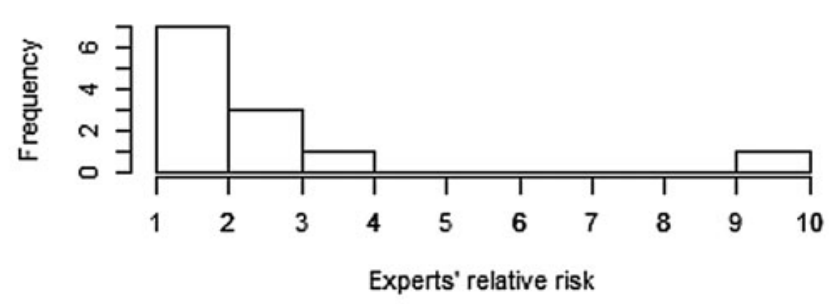

Criterion 13c

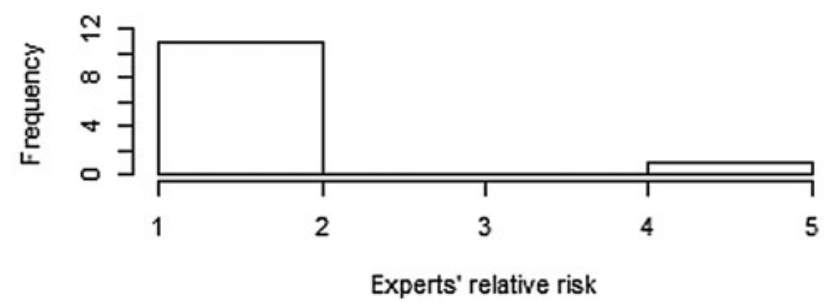

APPENDIX FIG. A1. (Continued). 
Criterion 13d

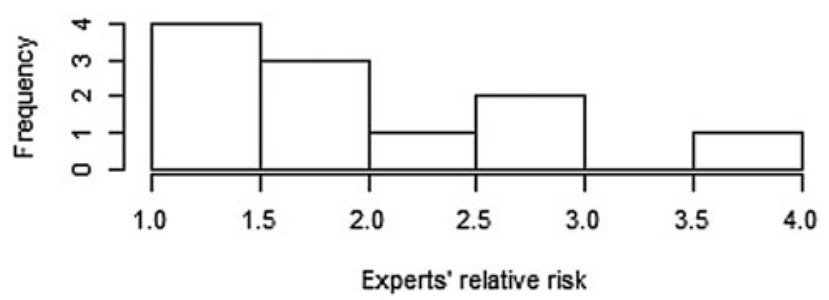

Criterion 14a

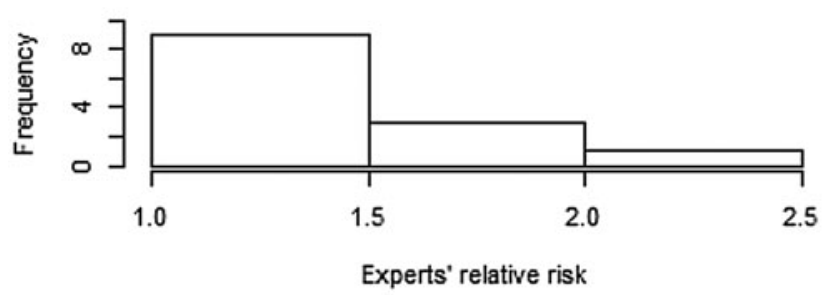

Criterion 14c

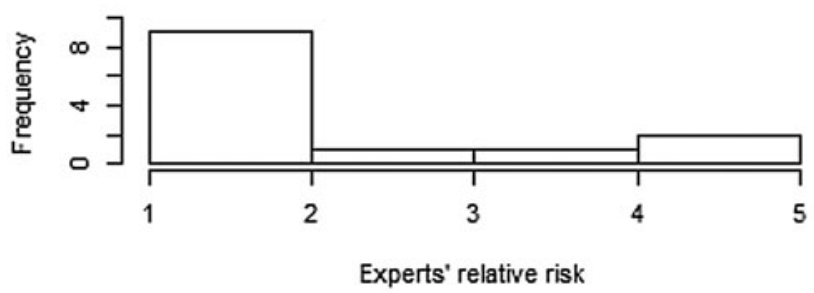

Criterion 14e

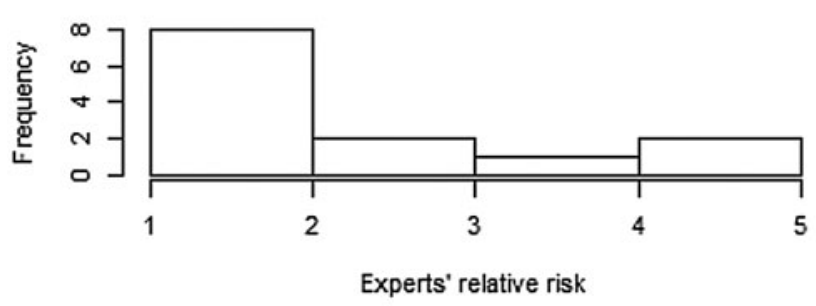

Criterion 14g

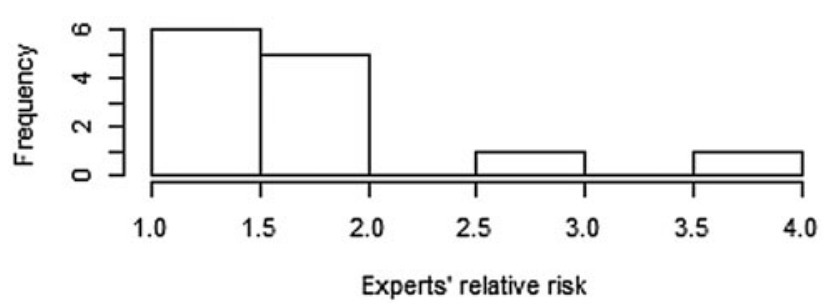

Criterion 13e

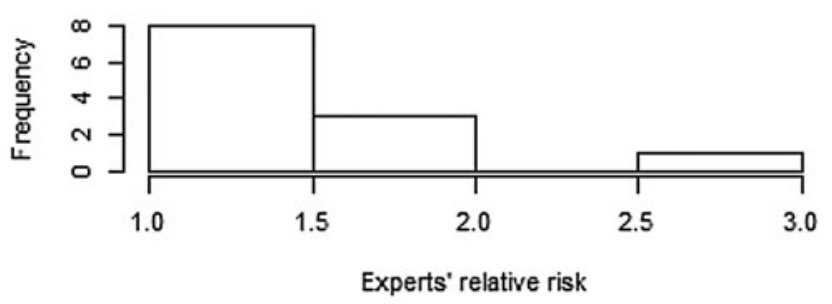

Criterion 14b

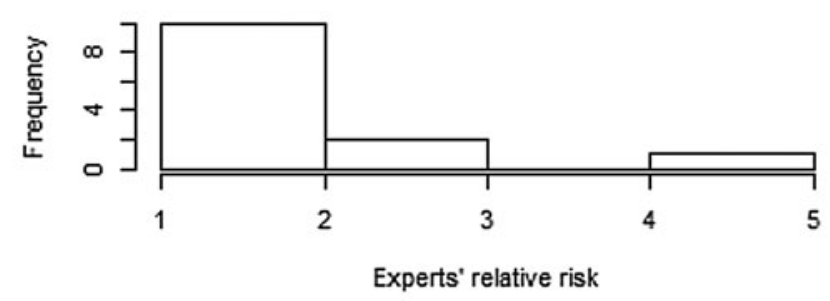

Criterion 14d

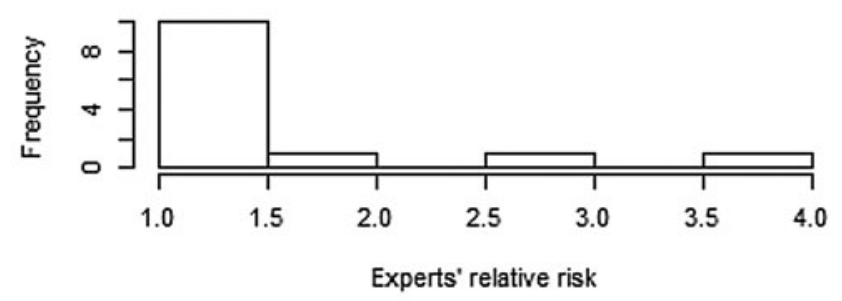

Criterion 14f

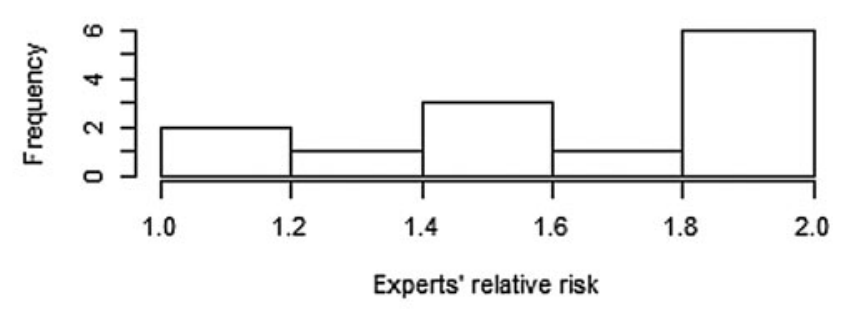

Criterion 15a

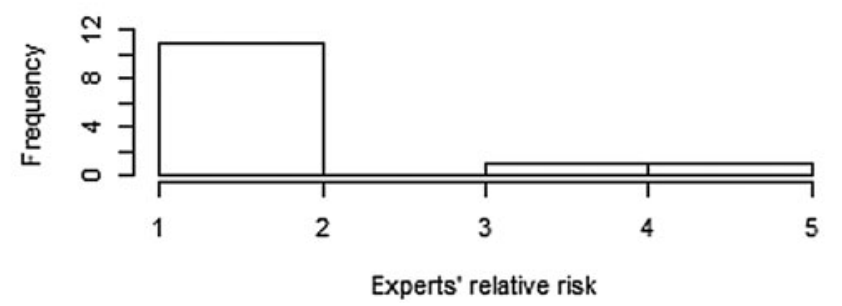

APPENDIX FIG. A1. (Continued). 
Criterion 15b

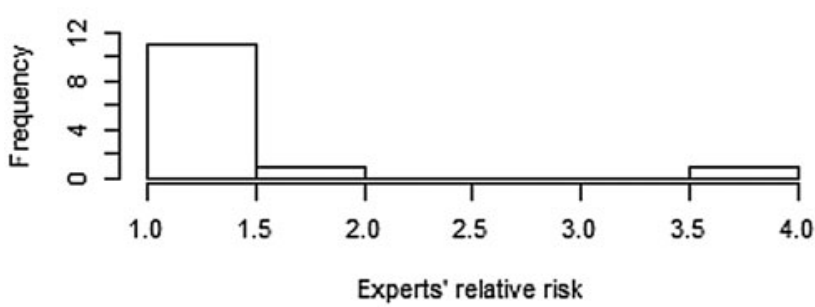

Criterion 17

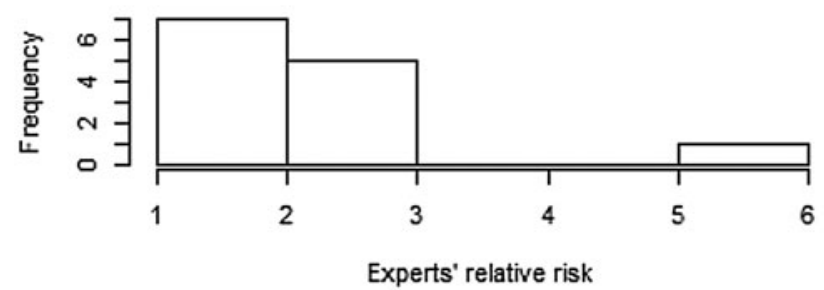

Criterion 19

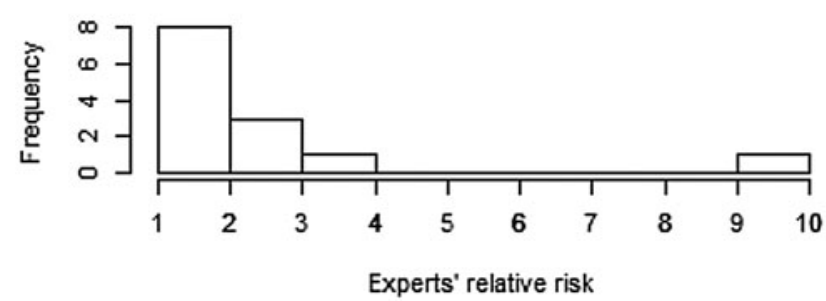

Criterion 21

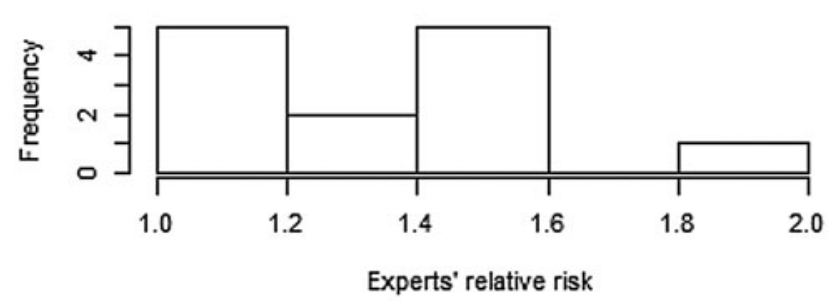

Criterion 22b

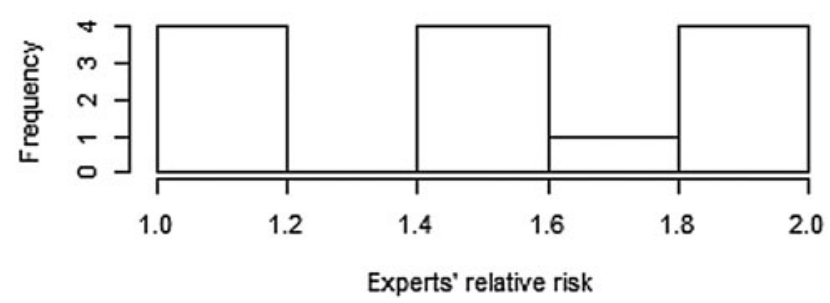

Criterion 16

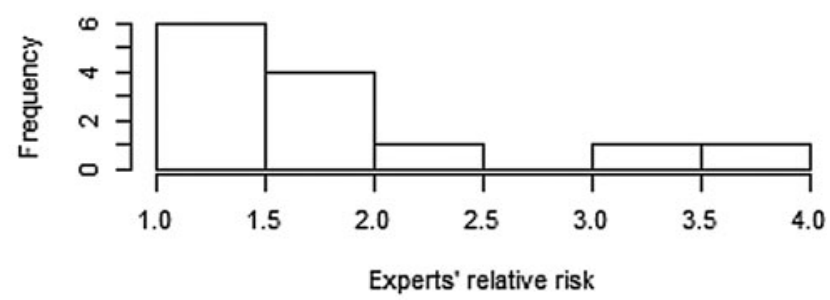

Criterion 18

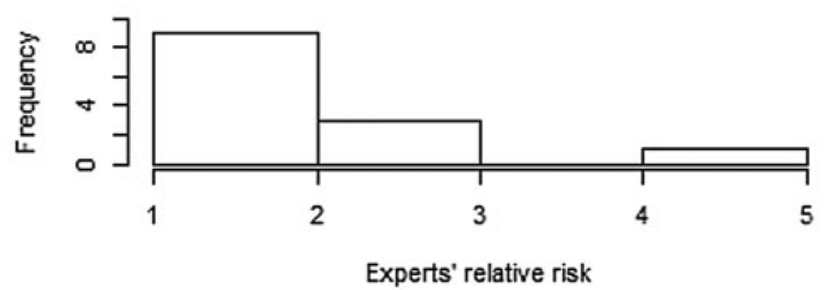

Criterion 20-cluster

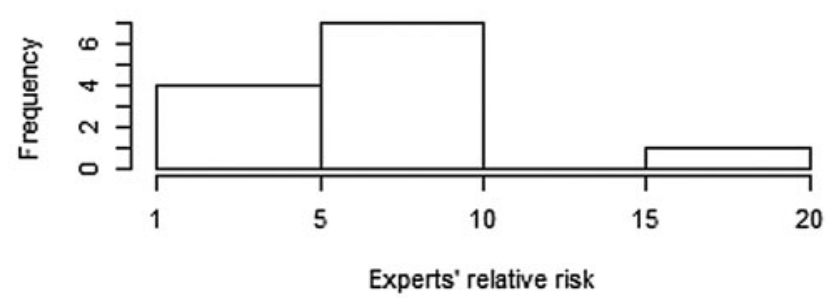

Criterion 22a

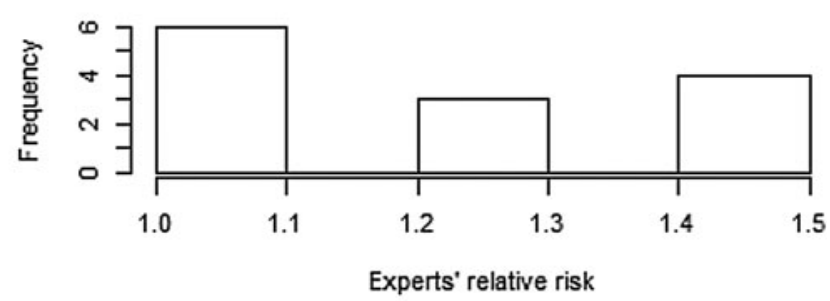

Criterion 22c

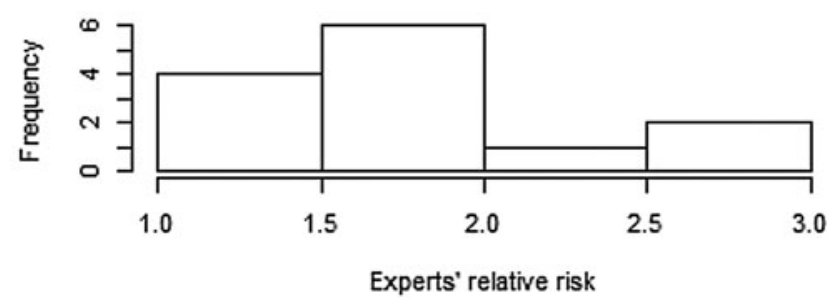

APPENDIX FIG. A1. (Continued). 
Criterion 23

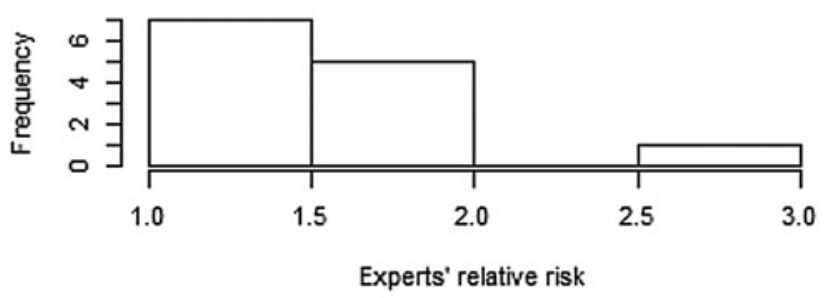

Criterion 24b

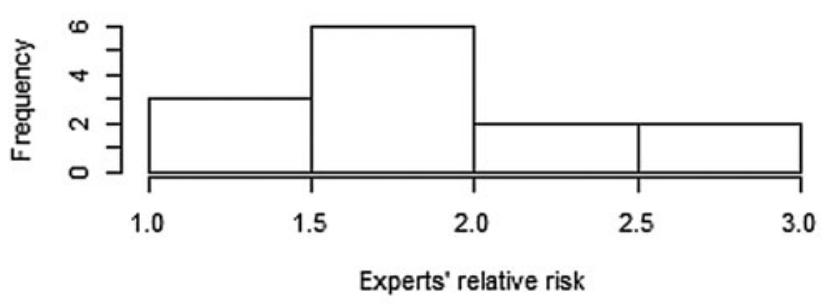

Criterion 25

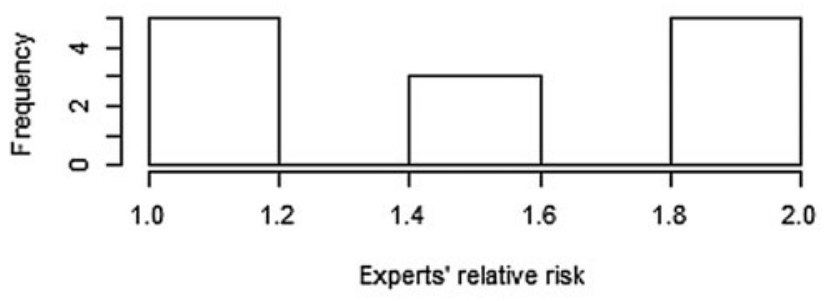

Criterion 26b

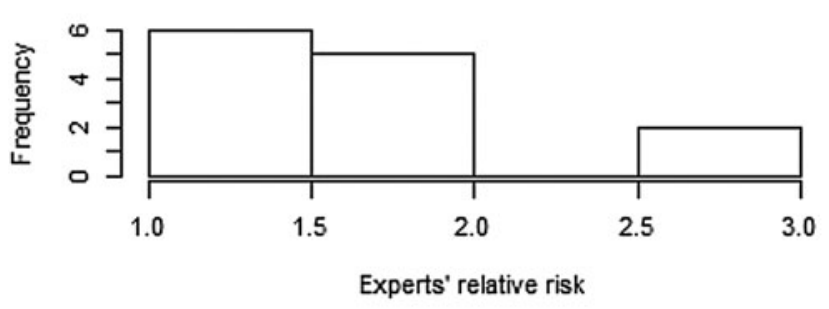

Criterion 27

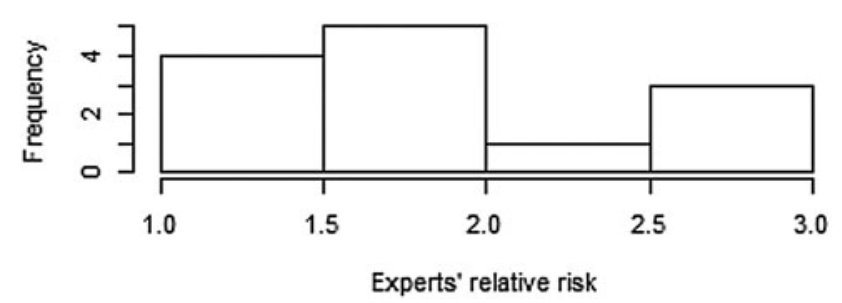

Criterion 24a

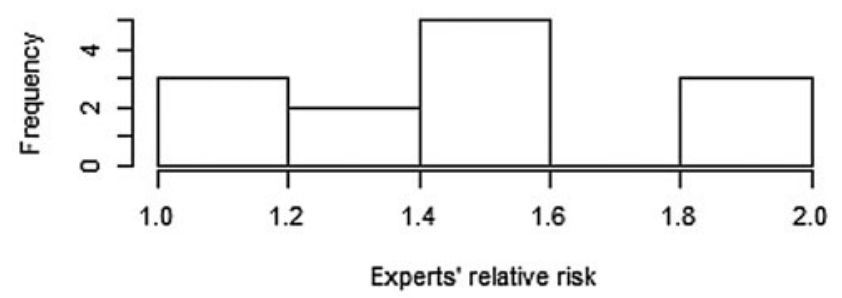

Criterion 24c

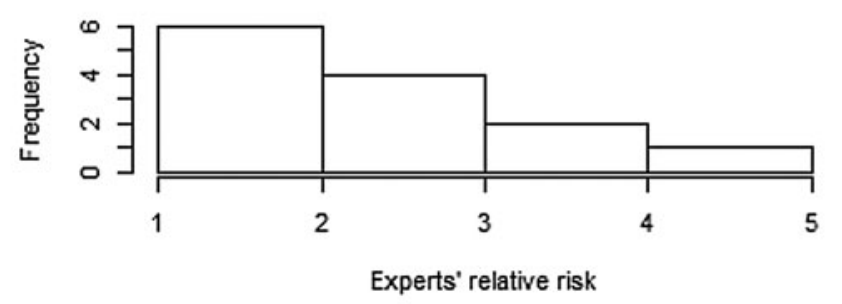

Criterion 26a

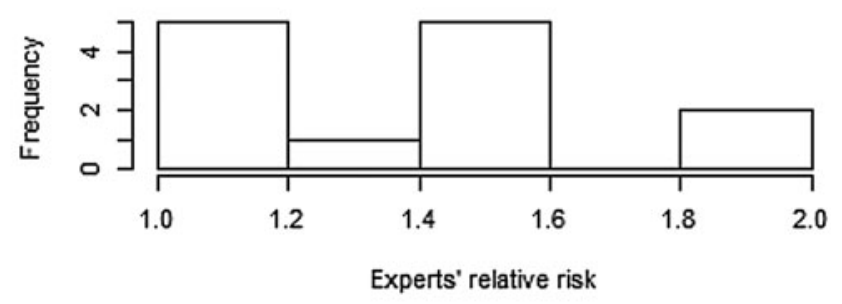

Criterion 26c

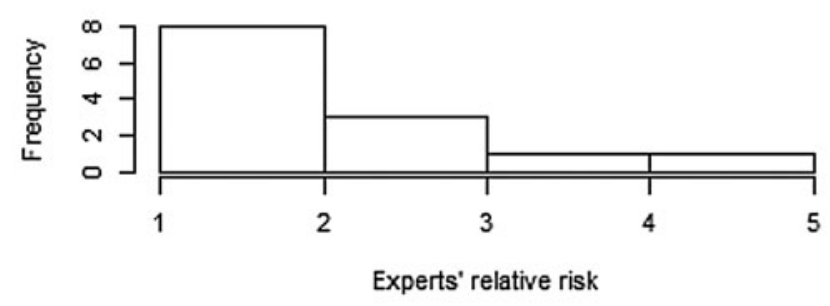

Criterion 28a

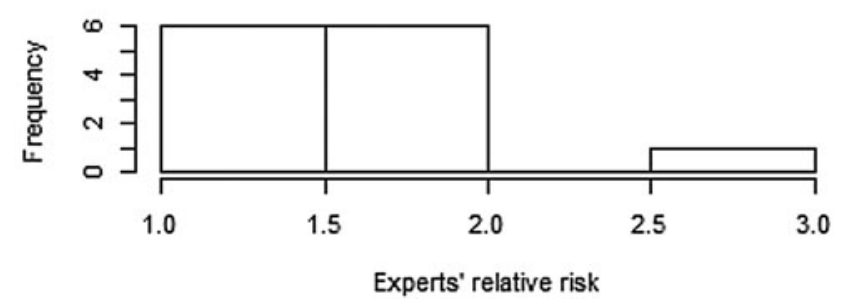

APPENDIX FIG. A1. (Continued). 
Criterion 28b

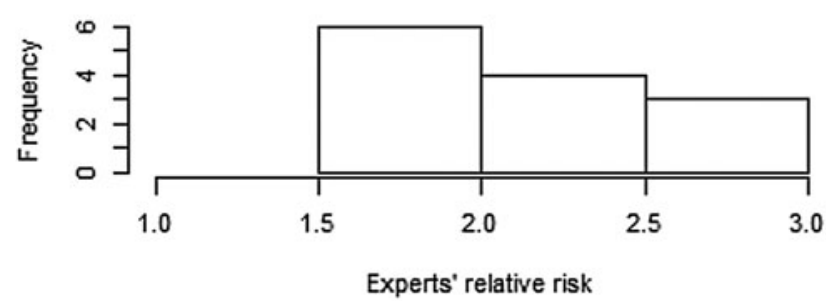

Criterion 29

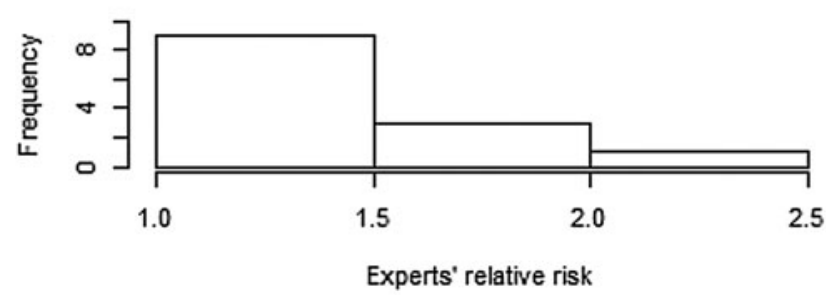

Criterion 30b

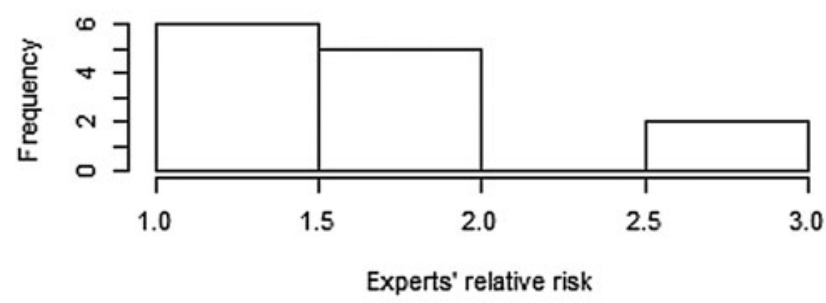

Criterion 31

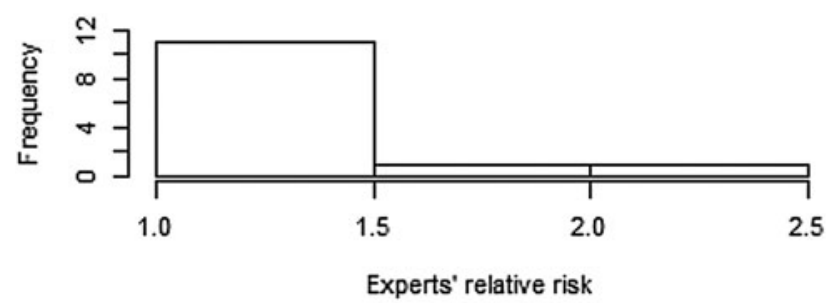

Criterion 32b

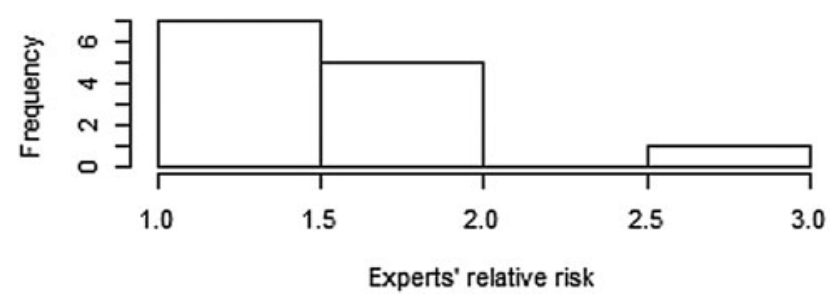

Criterion 28c

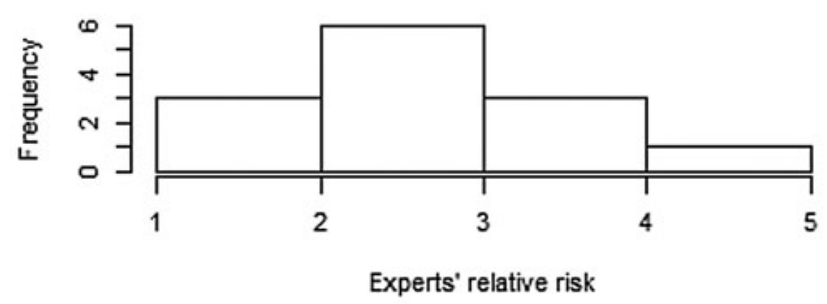

Criterion 30a

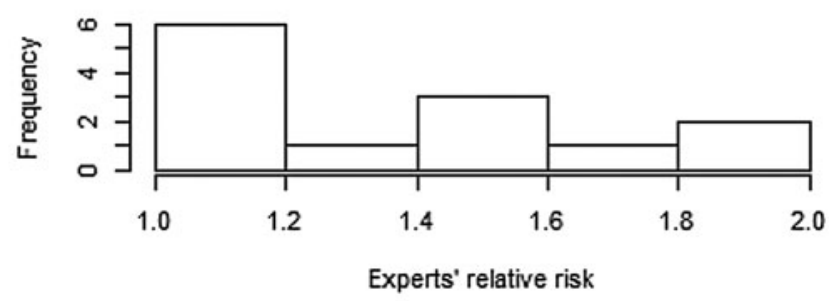

Criterion 30c

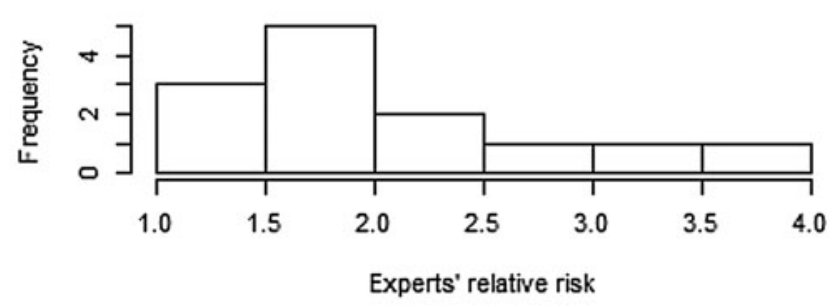

Criterion 32a

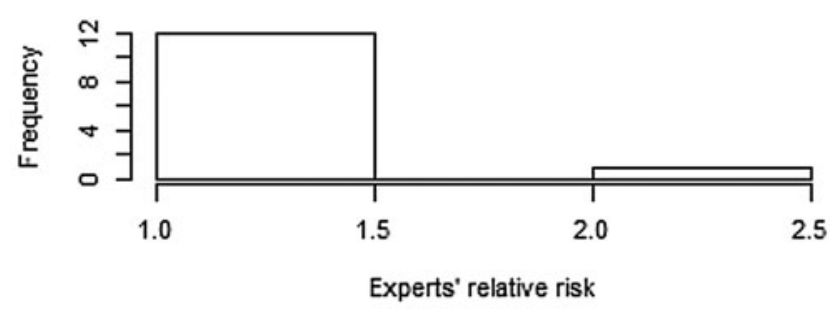

Criterion 32c

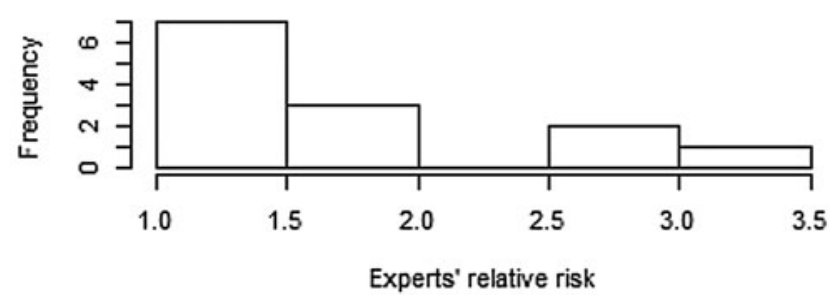

APPENDIX FIG. A1. (Continued). 
Criterion 33

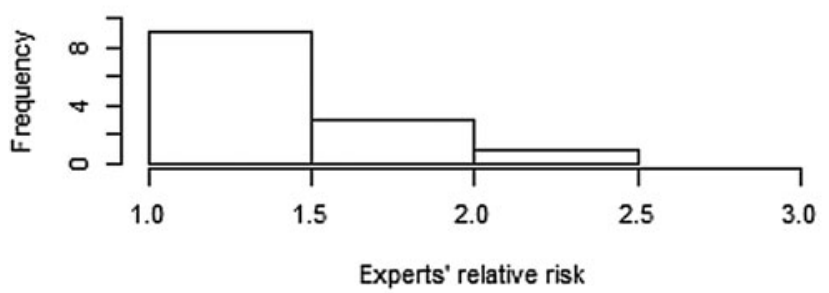

Criterion 34b

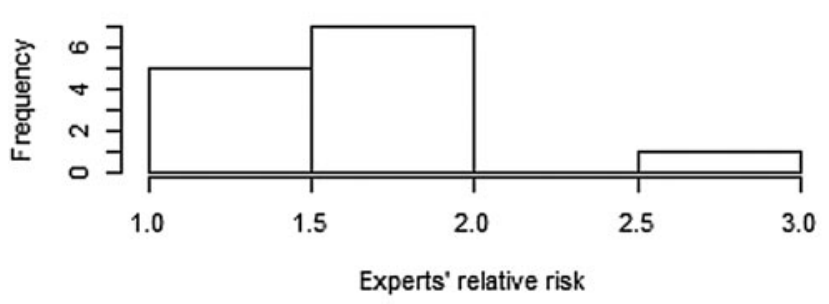

Criterion 35

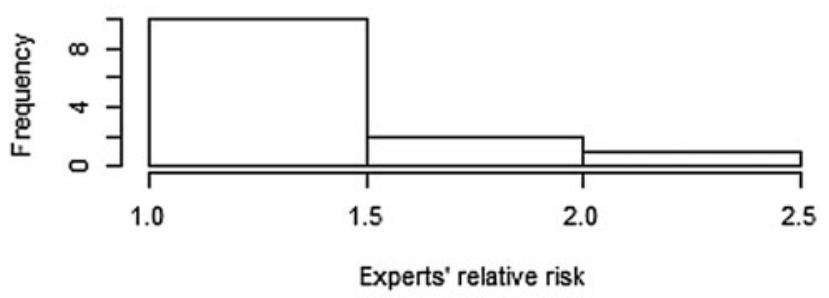

Criterion 36b

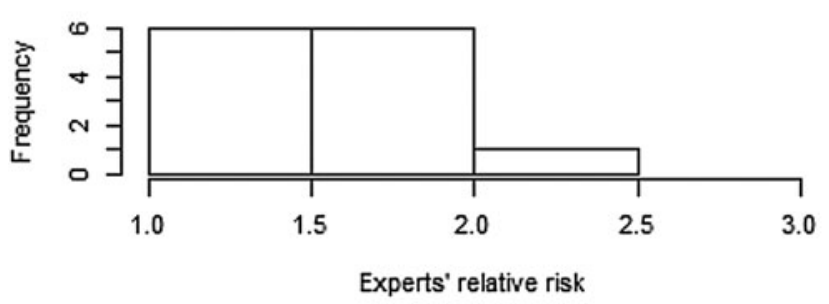

Criterion 37

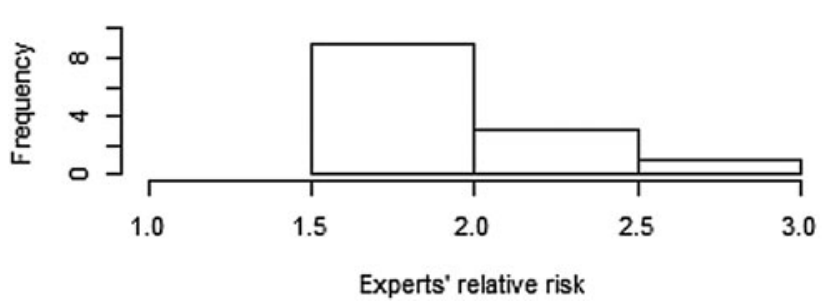

Criterion 34a

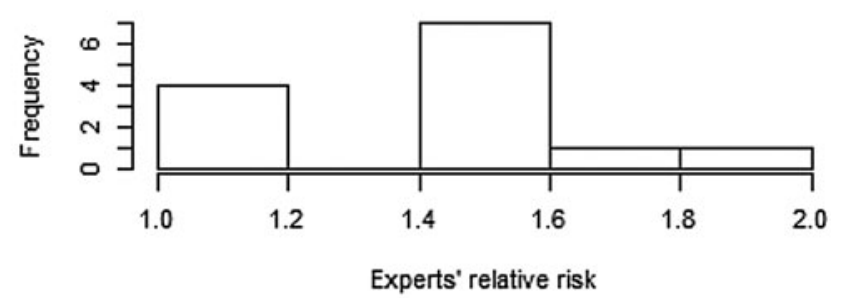

Criterion 34c

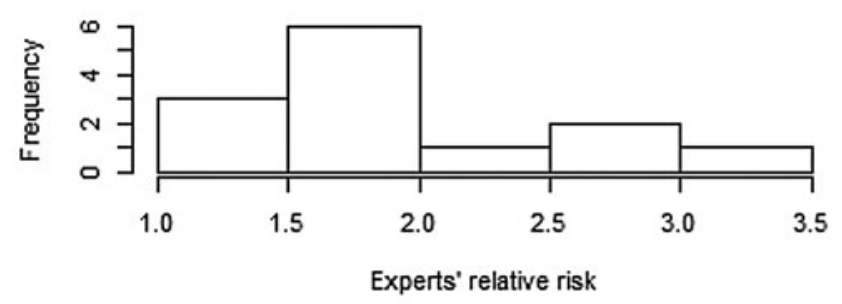

Criterion 36a

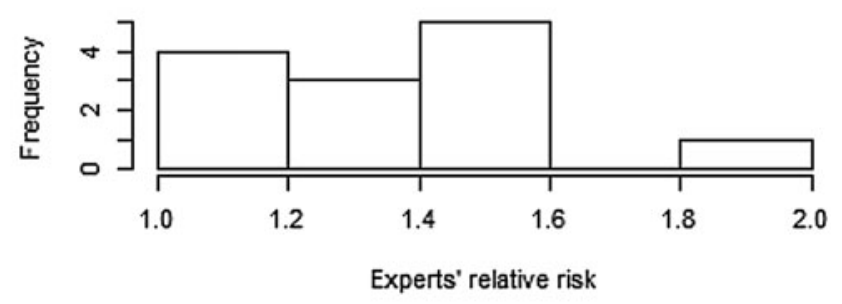

Criterion 36c

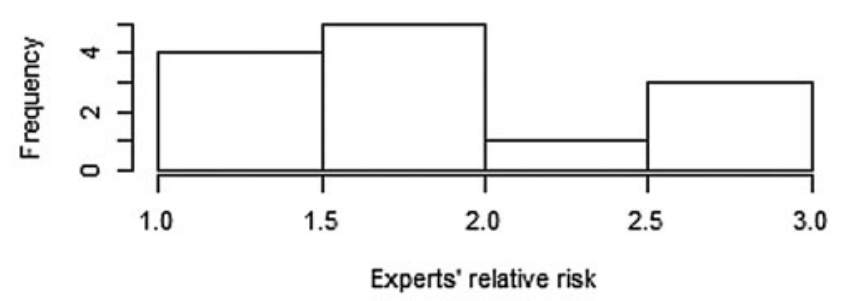

Criterion 38a

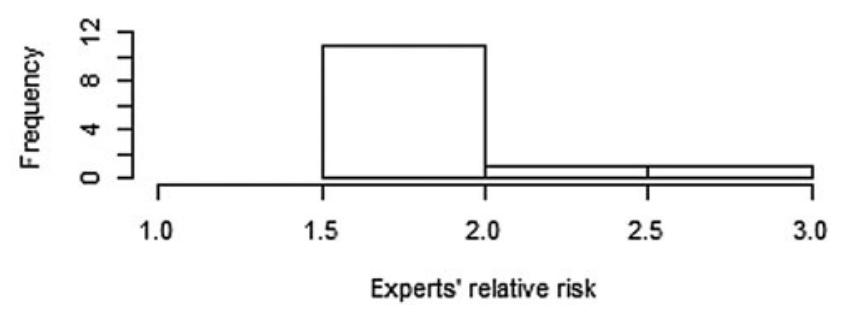

APPENDIX FIG. A1. (Continued). 
Criterion 38b

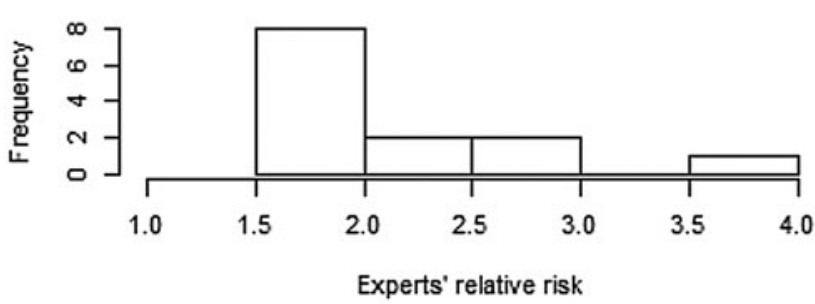

Criterion 39

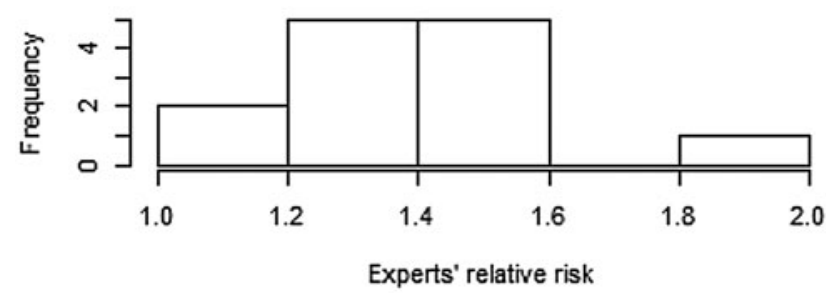

Criterion 40b

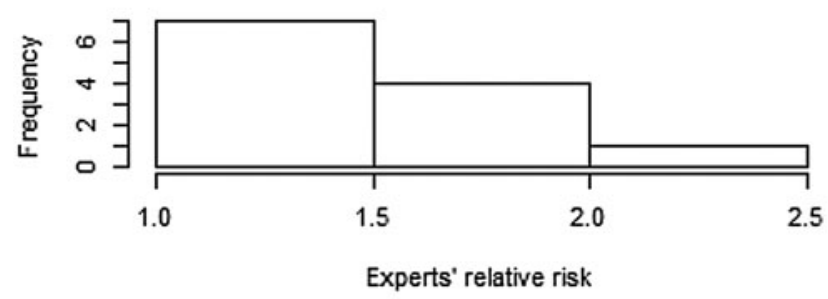

Criterion 41a

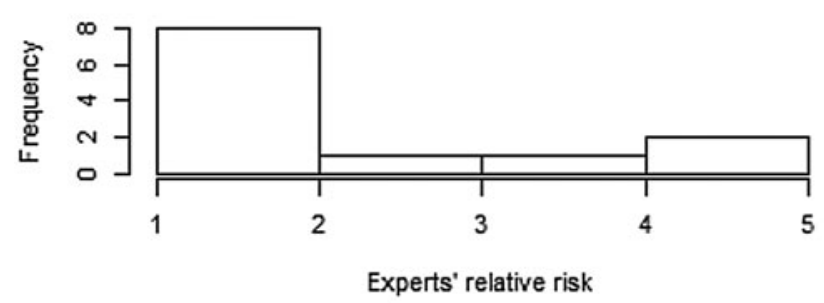

Criterion 41c

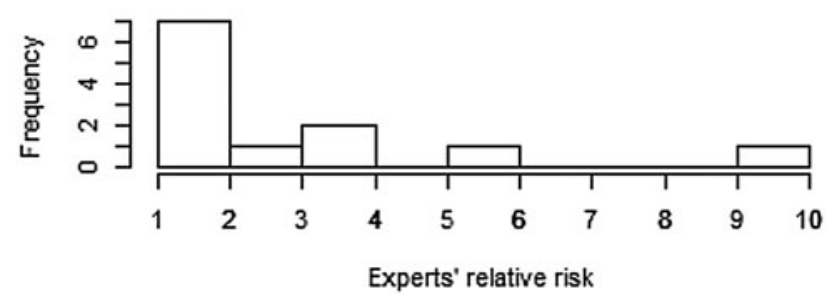

Criterion 38c

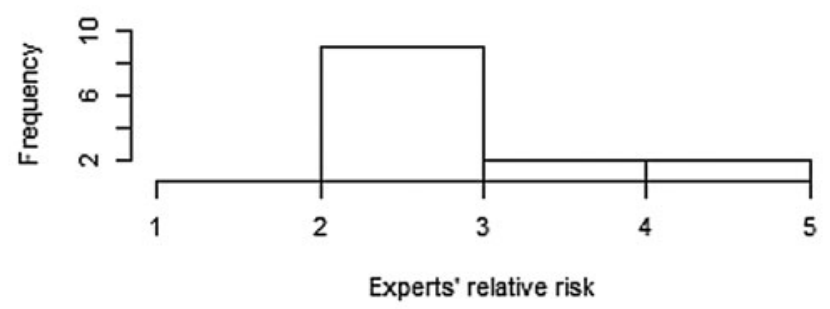

Criterion 40a

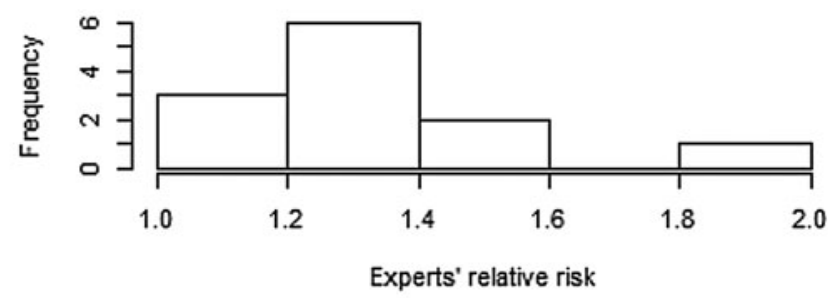

Criterion 40c

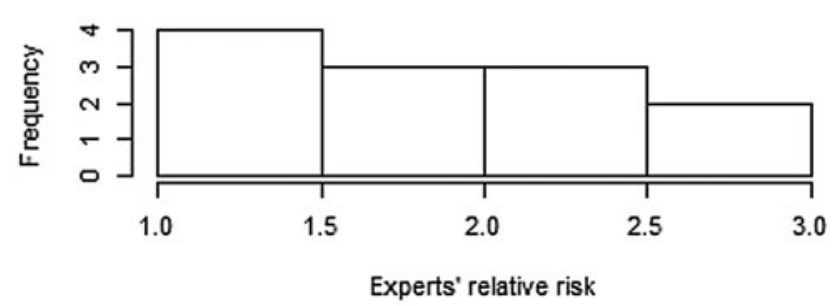

Criterion 41b

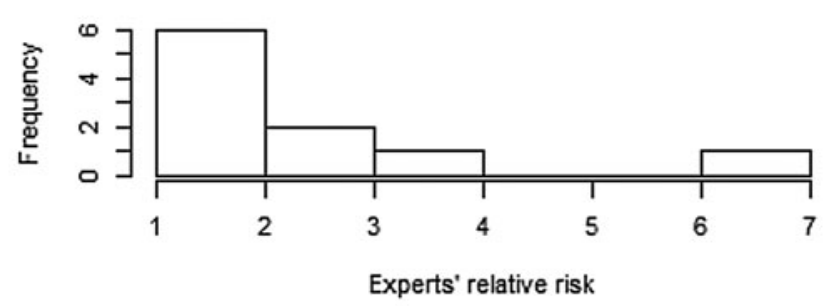

Criterion 41d

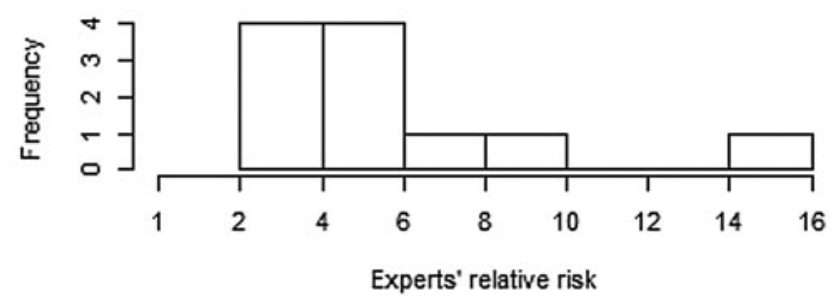

APPENDIX FIG. A1. (Continued). 
Criterion 41e

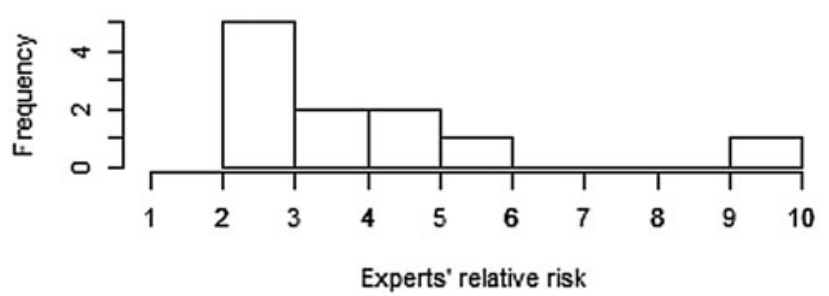

Criterion 41g

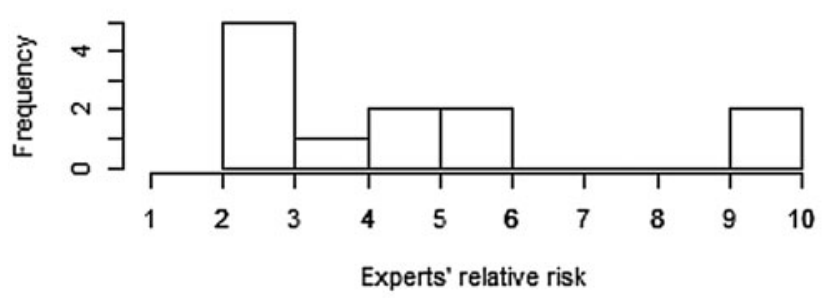

Criterion 43a

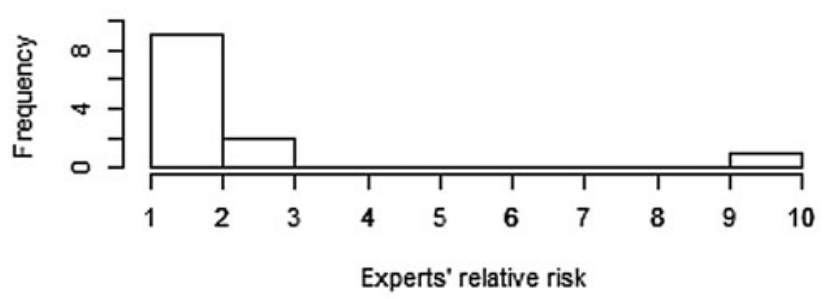

Criterion 43c

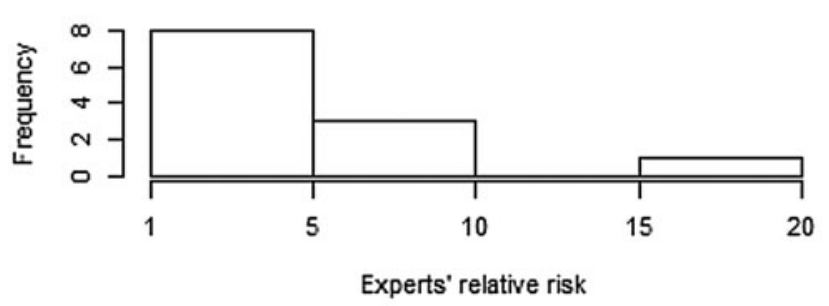

Criterion 45a

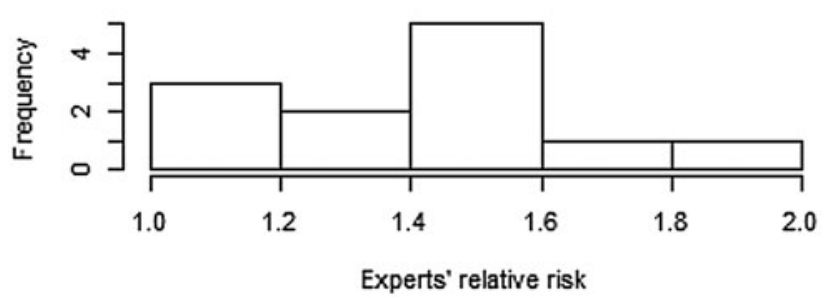

Criterion 41f

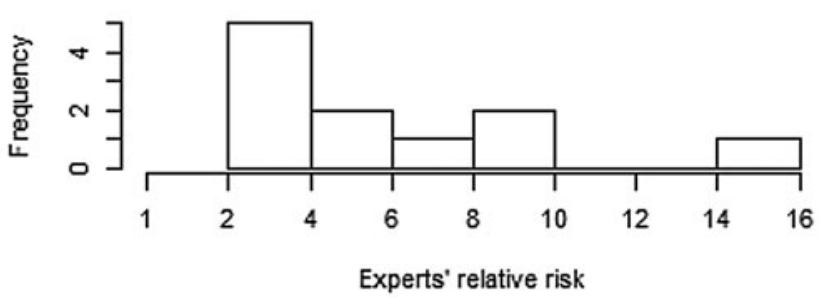

Criterion 42-cluster

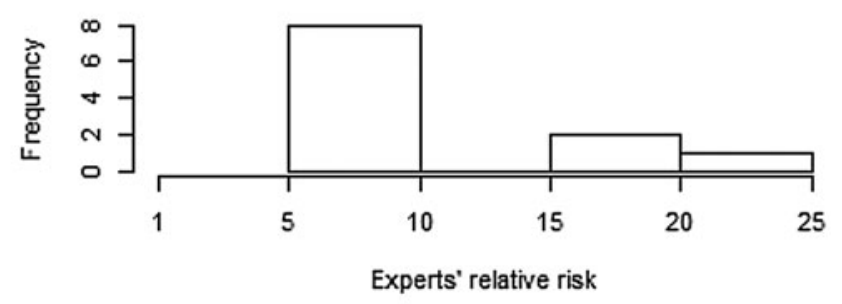

Criterion 43b

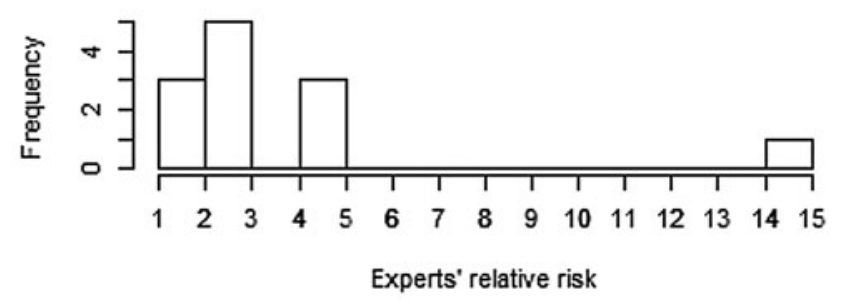

Criterion 44

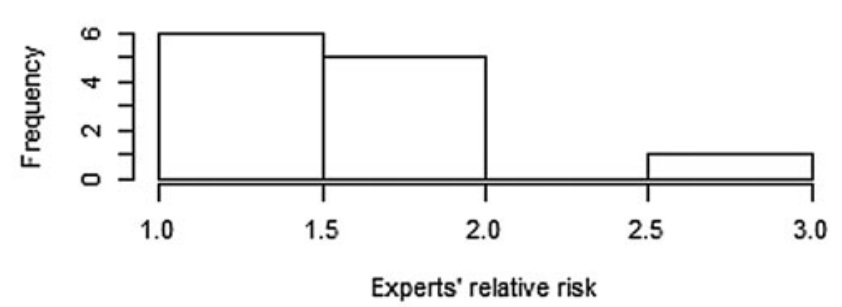

Criterion 45b

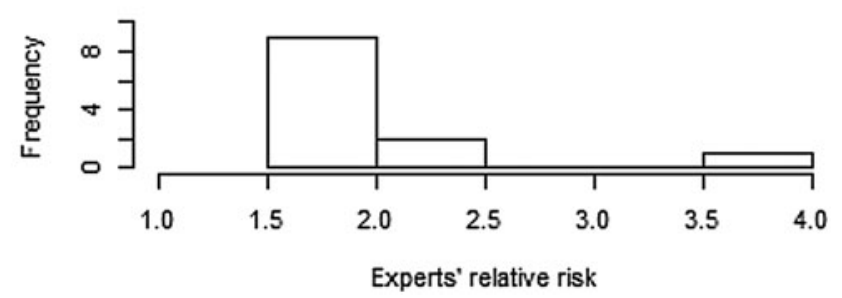

APPENDIX FIG. A1. (Continued). 
Criterion 45c

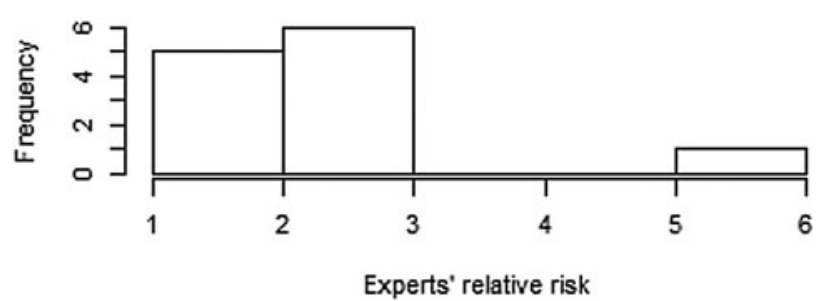

Criterion 47a

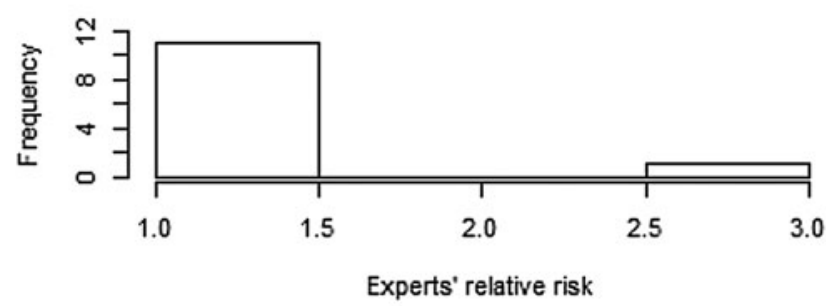

Criterion 47c

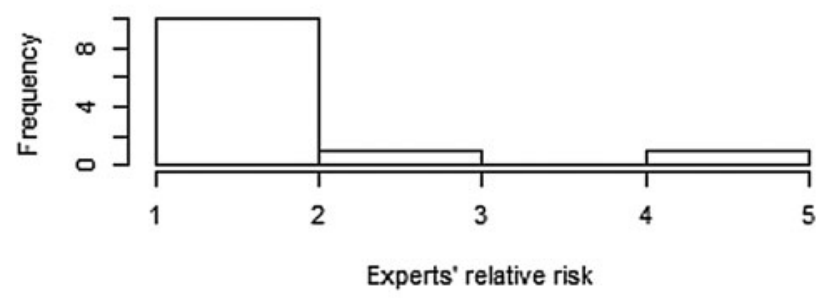

Criterion 49a

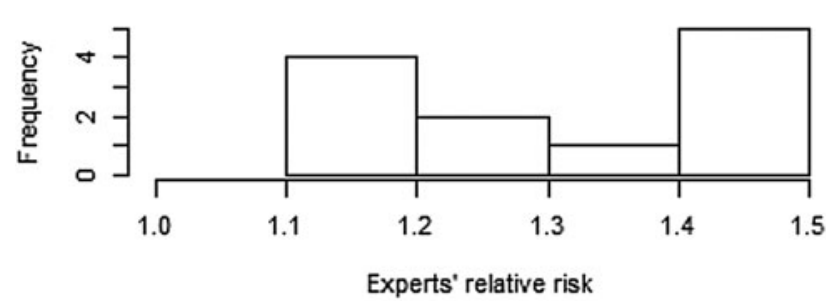

Criterion 49c

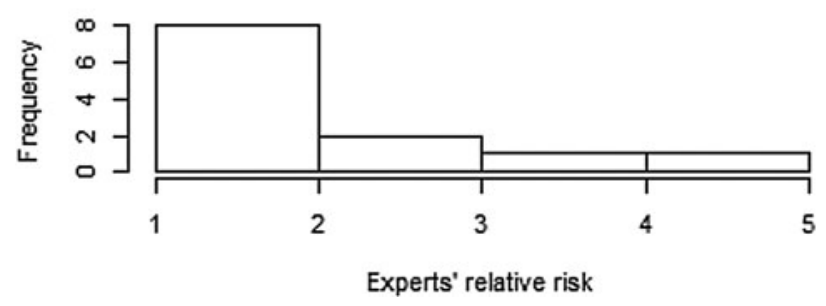

Criterion $\mathbf{4 6}$

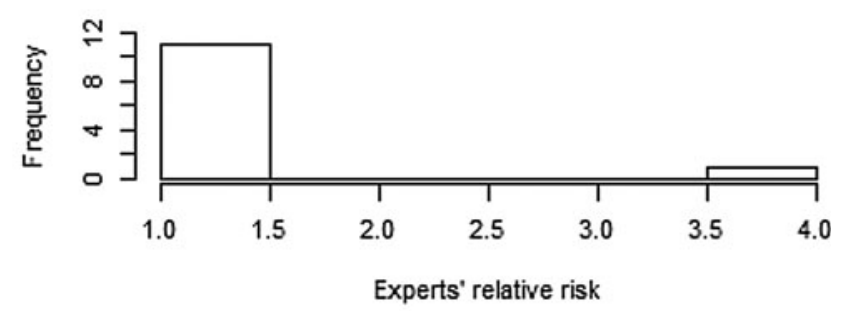

Criterion 47b

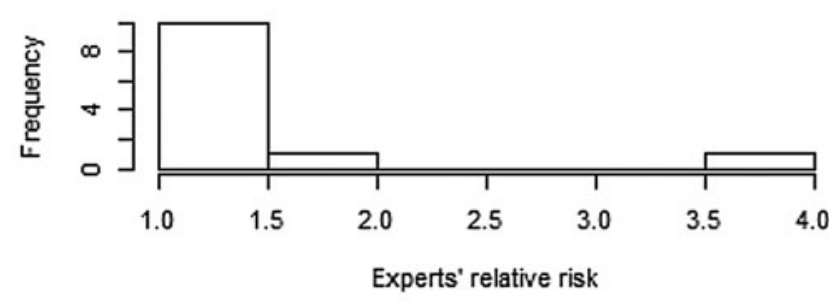

Criterion 48

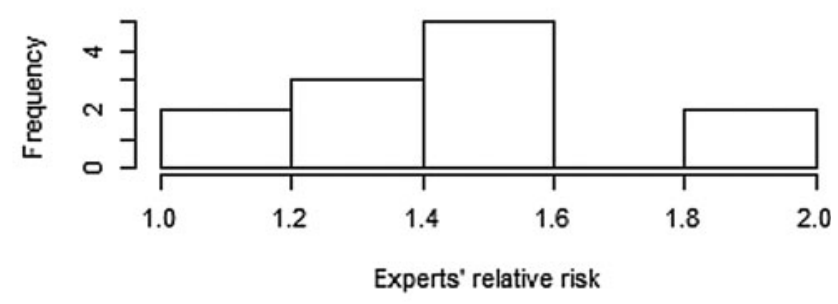

Criterion 49b

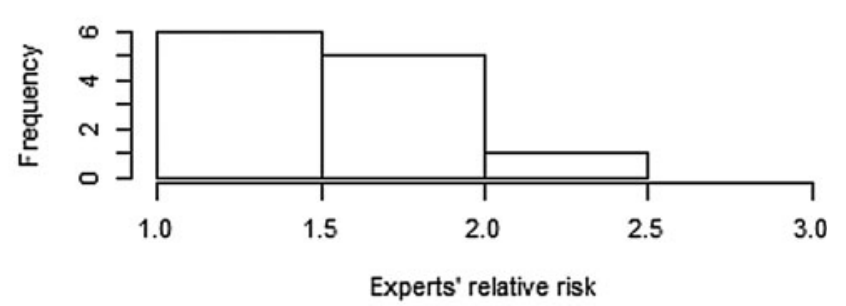

Criterion 50-cluster

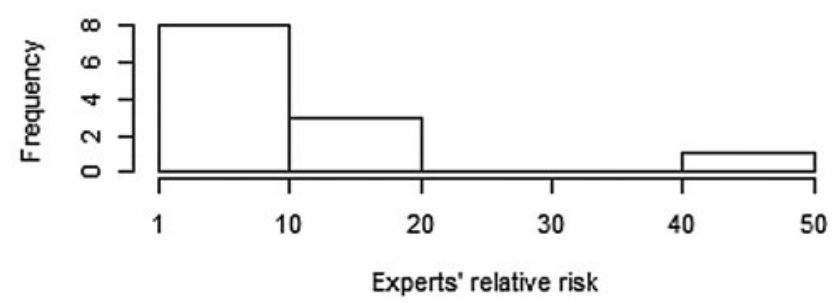

APPENDIX FIG. A1. (Continued). 
Inherent Risk Factors
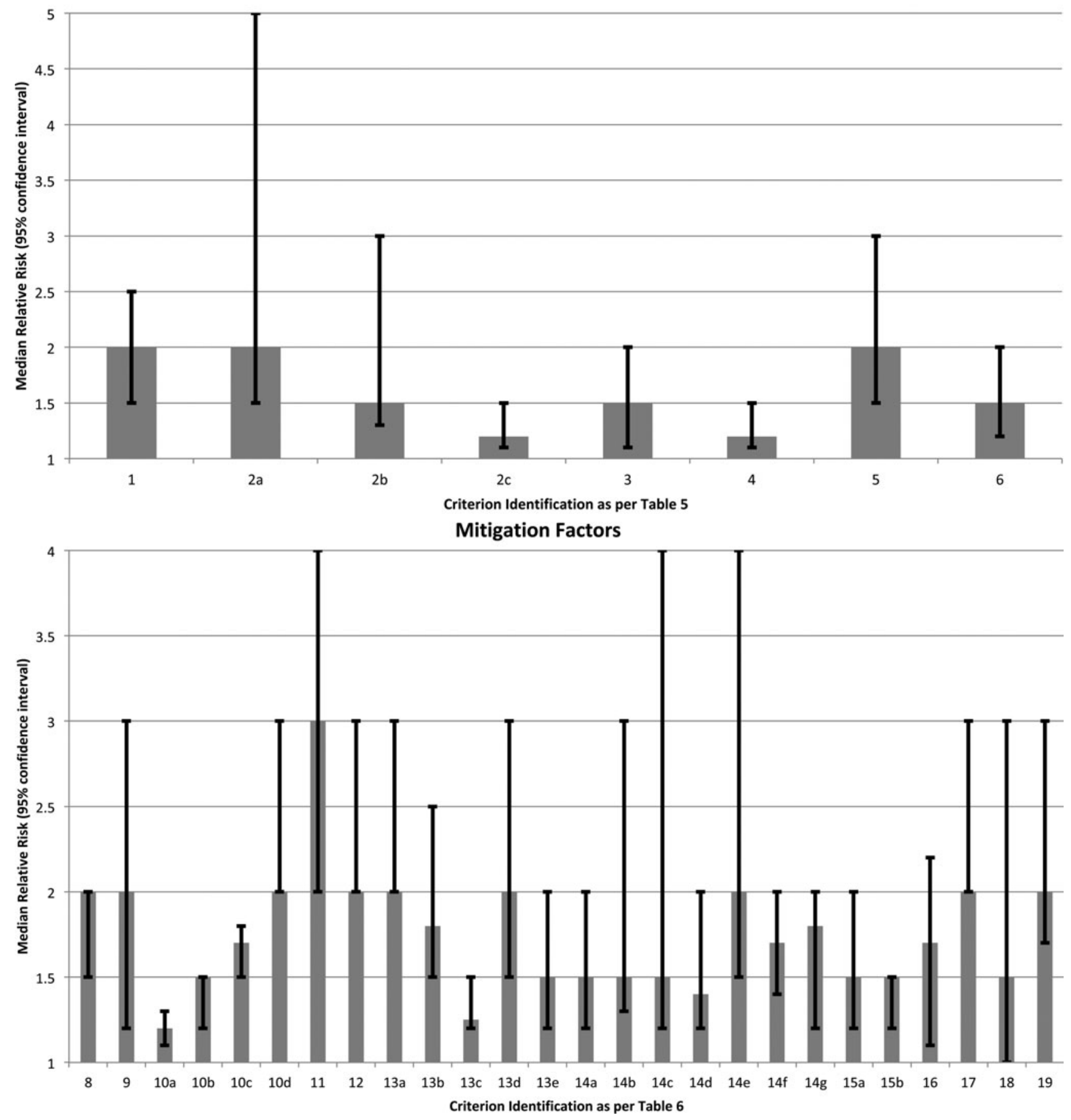

APPENDIX FIG. A2. Bar chart of median relative risks for each criterion grouped by clusters with 95\% confidence intervals for median. 


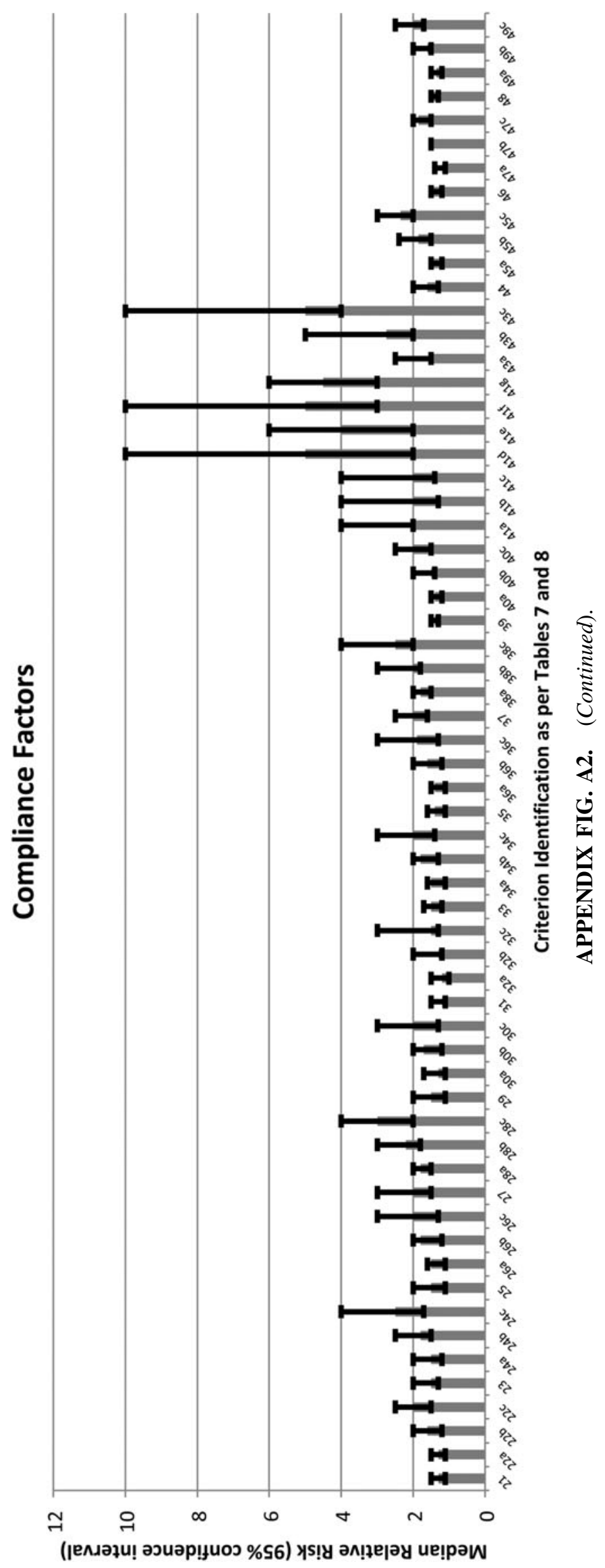

